OPEN ACCESS

Edited by:

Enrica Maria Petrini,

Fondazione Istituto Italiano di

Tecnologia, Italy

Reviewed by:

Igor Medina,

Institut National de la Santé et de la

Recherche Médicale (INSERM),

France

Tarek Deeb,

Tufts University School of Medicine,

United States

*Correspondence:

Sabine Lévi

sabine.levi@inserm.fr

tThese authors have contributed equally to this work

Received: 01 August 2018 Accepted: 01 February 2019 Published: 20 February 2019

Citation:

Côme E, Heubl M, Schwartz EJ, Poncer JC and Lévi S

(2019) Reciprocal Regulation of KCC2 Trafficking and

Synaptic Activity.

Front. Cell. Neurosci. 13:48. doi: $10.3389 /$ fncel.2019.00048

\section{Reciprocal Regulation of KCC2 Trafficking and Synaptic Activity}

\author{
Etienne Côme ${ }^{1,2,3 t}$, Martin Heubl ${ }^{1,2,3 t}$, Eric J. Schwartz ${ }^{1,2,3}$, Jean Christophe Poncer ${ }^{1,2,3}$ \\ and Sabine Lévi ${ }^{1,2,3 *}$
}

${ }^{1}$ INSERM UMR-S 1270, Paris, France, ${ }^{2}$ Sorbonne Université, Paris, France, ${ }^{3}$ Institut du Fer à Moulin, Paris, France

The main inhibitory neurotransmitter receptors in the adult central nervous system (CNS) are type $A \gamma$-aminobutyric acid receptors $\left(G_{A B A} R s\right)$ and glycine receptors (GlyRs). Synaptic responses mediated by GlyR and $G_{A B A} R$ display a hyperpolarizing shift during development. This shift relies mainly on the developmental up-regulation of the $\mathrm{K}^{+}-\mathrm{Cl}^{-}$ co-transporter KCC2 responsible for the extrusion of $\mathrm{Cl}^{-}$. In mature neurons, altered KCC2 function-mainly through increased endocytosis-leads to the re-emergence of depolarizing GABAergic and glycinergic signaling, which promotes hyperexcitability and pathological activities. Identifying signaling pathways and molecular partners that control KCC2 surface stability thus represents a key step in the development of novel therapeutic strategies. Here, we present our current knowledge on the cellular and molecular mechanisms governing the plasma membrane turnover rate of the transporter under resting conditions and in response to synaptic activity. We also discuss the notion that KCC2 lateral diffusion is one of the first parameters modulating the transporter membrane stability, allowing for rapid adaptation of $\mathrm{Cl}^{-}$transport to changes in neuronal activity.

Keywords: $\mathrm{GABA}_{\mathrm{A}} \mathrm{R}$, chloride homeostasis, membrane turnover, lateral diffusion, clustering

\section{INTRODUCTION}

Excitatory and inhibitory neurotransmission depend on the electrochemical ion gradients across the plasma membrane. The activation of postsynaptic ionotropic glutamate receptors leads to an influx of positively charged ions and thereby generates a depolarizing, excitatory postsynaptic potential (EPSP). In contrast, the net effect of activation of ionotropic anion permeable channels, such as type $\mathrm{A} \gamma$-aminobutyric acid receptors $\left(\mathrm{GABA}_{\mathrm{A}} \mathrm{Rs}\right)$ or glycine receptors (GlyRs), depends on the gradient of anions across the plasma membrane, predominantly chloride $\left(\mathrm{Cl}^{-}\right)$and bicarbonate $\left(\mathrm{HCO}_{3}{ }^{-}\right.$; Bormann et al., 1987; Kaila and Voipio, 1987). The chloride gradient is mainly established by two secondary active transporters: the $\mathrm{K}^{+}{ }_{-} \mathrm{Cl}^{-}$cotransporter KCC2 that extrudes chloride out of the neuron using the potassium gradient (generated by the $\mathrm{Na}^{+} / \mathrm{K}^{+}$ATPase), and the $\mathrm{Na}^{+}-\mathrm{K}^{+}-\mathrm{Cl}^{-}$cotransporter NKCC1 which usually transports chloride into the neuron based on transmembrane sodium and potassium gradients also generated by the $\mathrm{Na}^{+} / \mathrm{K}^{+}$ATPase (Figure 1). Hence, the balance of expression and activity of these transporters influence intracellular chloride concentration $\left(\left[\mathrm{Cl}^{-}\right]_{\mathrm{i}}\right)$ and the efficacy and polarity of GABAergic and glycinergic transmission. In immature neurons, where NKCC1 expression 


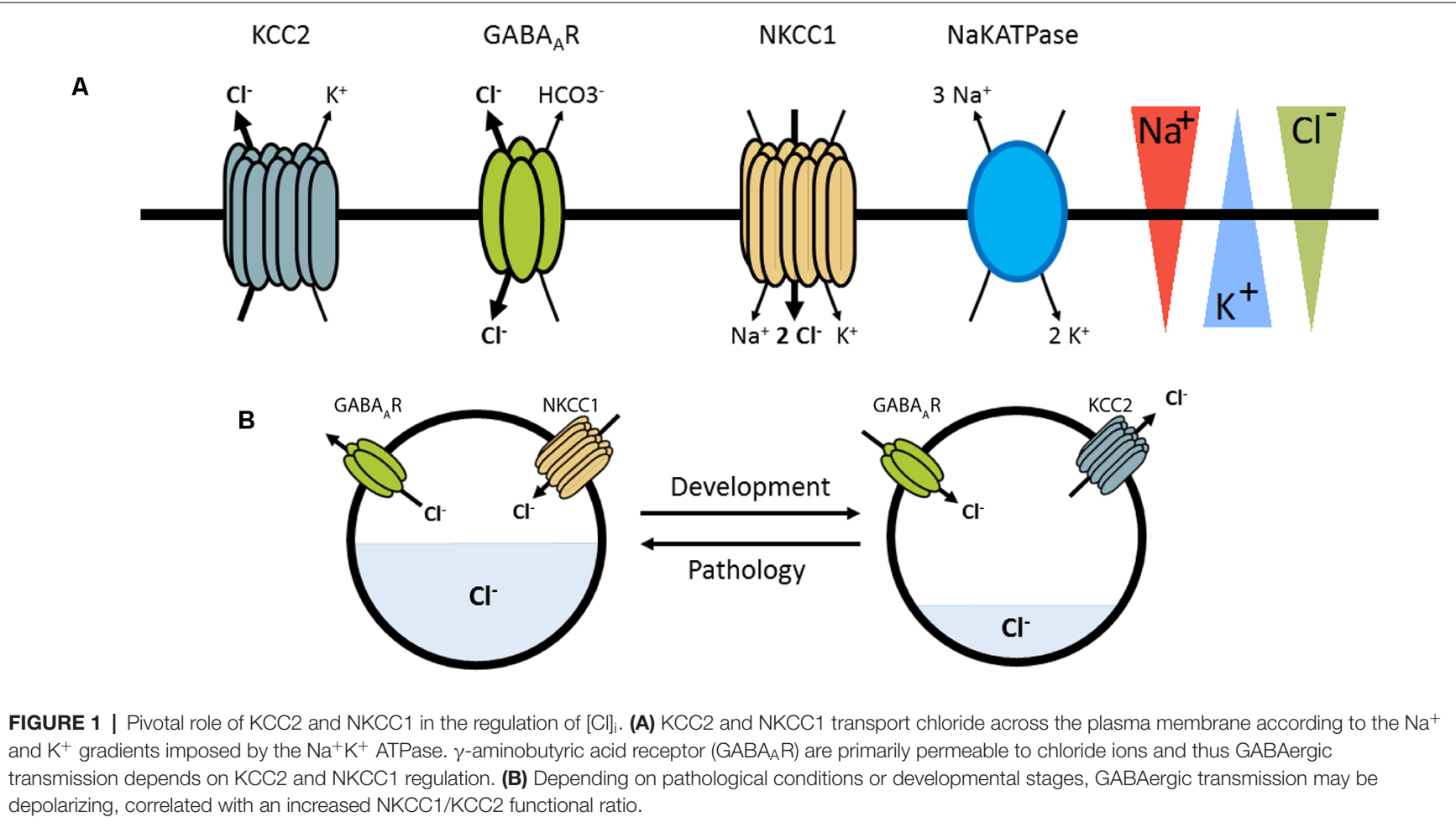

predominates, high $\left[\mathrm{Cl}^{-}\right]_{\mathrm{i}}$ is associated with depolarizing responses to $\mathrm{GABA}$ and glycine reflecting $\mathrm{Cl}^{-}$efflux. In contrast, an increased expression of KCC2 in mature neurons lowers $\left[\mathrm{Cl}^{-}\right]_{\mathrm{i}}$ leading to an influx of $\mathrm{Cl}^{-}$ions and hyperpolarizing responses upon $\mathrm{GABA}_{\mathrm{A}} \mathrm{R} / \mathrm{GlyR}$ activation.

In addition to its role in maintaining low $\left[\mathrm{Cl}^{-}\right]_{\mathrm{i}}$, KCC2 regulates the formation (Li et al., 2007), functional maintenance and plasticity (Gauvain et al., 2011; Fiumelli et al., 2013; Chevy et al., 2015; Llano et al., 2015) of glutamatergic synapses. Consistent with its key role in regulating inhibitory and excitatory neurotransmission, alterations in KCC2 expression and function have emerged as a common mechanism underlying pathological activity in a variety of neurological and psychiatric disorders (Medina et al., 2014; Kahle and Delpire, 2016; Moore et al., 2017; Wang et al., 2018). Understanding the mechanisms regulating KCC2 expression and function is therefore crucial to develop novel and efficient therapeutic strategies. Here, we will review the cellular and molecular mechanisms controlling KCC2 turnover and describe how these mechanisms are rapidly tuned when neuronal activity is challenged.

\section{KCC2 STRUCTURE AND REGULATORY SEQUENCES}

KCC2 is one of nine members of the cation-chloride co-transporter (CCC) family encoded by the genes Slc12a1-9. KCC2 is a glycoprotein of $120 \mathrm{kDa}$ with a predicted structure of 12 transmembrane segments (TMs), six extracellular loops flanked by a short intracellular amino terminal domain (NTD; amino acids 1-103) and a long intracellular carboxy-terminal domain (CTD; last 500 amino acids; Hartmann and Nothwang, 2015; Figure 2).

Two different KCC2 isoforms, KCC2a and KCC2b, are produced by use of alternative promoters of the Slc12a5 gene encoding KCC2 (Uvarov et al., 2007). The NTD of KCC2a is 23 amino acids longer than the KCC2b one (Uvarov et al., 2007) and contains a putative SPAK (STE20/SPS1-related, proline alanine-rich kinase) and OSR1 kinase (Oxydative stress response 1) interaction site (de Los Heros et al., 2014; Table 1). Both isoforms show similar ion transport properties when expressed in human embryonic kidney (HEK) 293 cells and cultured hippocampal and cortical neurons (Uvarov et al., 2007; Markkanen et al., 2017), but have different subcellular localization in vivo (in neurons of the deep cerebellar nucleus, the pons and the medulla) and in vitro (cultured hippocampal neurons; Markkanen et al., 2014, 2017), suggesting a contribution of the NTD to the subcellular targeting of the transporter in given cells, probably via the binding to selective partners.

Based on a study of KCC1 (Casula et al., 2001), the KCC2 NTD has been suggested to be mandatory for KCC2 function (Li et al., 2007). Several groups have therefore used KCC2 lacking the NTD (KCC2- $\triangle$ NTD) to study ion-transport independent roles of KCC2 (Li et al., 2007; Horn et al., 2010; Fiumelli et al., 2013). The group of Igor Medina recently described altered exocytosis by truncation of the NTD in N2a cells, HEK 293 cells and cultured hippocampal neurons (Friedel et al., 2017).

In addition to five short extracellular loops, KCC2 contains a long extracellular loop (LEL) between TM5 and TM6 of around 100 amino acids (Williams et al., 1999). Based on 


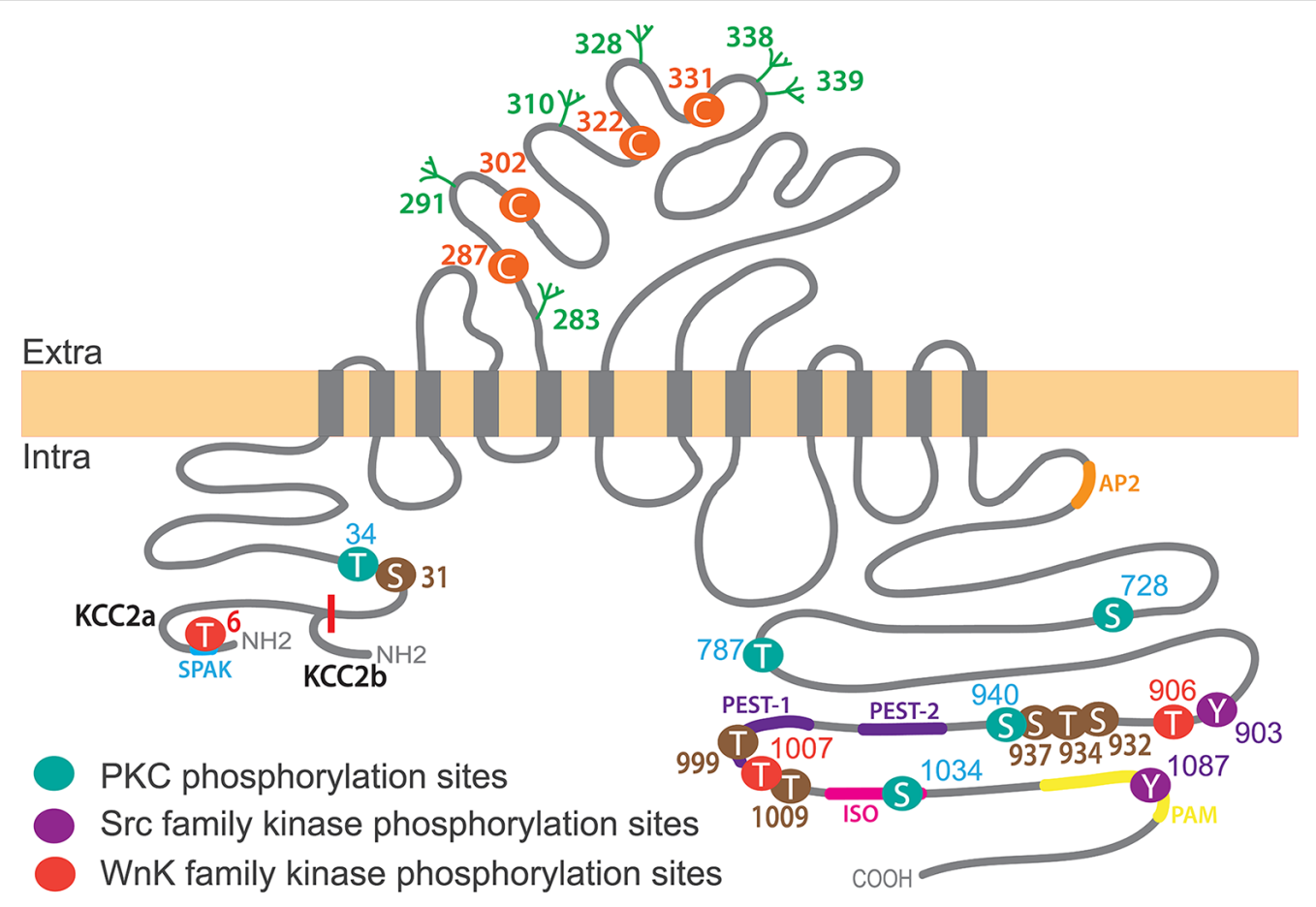

FIGURE 2 | KCC2 structure, key phosphorylation residues and regulatory domains. The KCC2 co-transporter is a $\sim 140$ kDa protein with a predicted topology of 12 membrane spanning segments, an extracellular domain between transmembrane domains 5 and 6 containing N-glycosylation sites (green) and key Cysteine residues for ion transport (orange), and is flanked by two cytoplasmic carboxy- and amino- terminal domains. All residues (besides Threonine T6 which is only present in $\mathrm{KCC} 2 \mathrm{a}$ ) are numbered according to human $\mathrm{KCC} 2 \mathrm{~b}$. Note that the mouse sequence lacks amino acid 1,000 and thus beyond this residue the numbering is shifted (e.g., T1007 in human corresponds to T1006 in mice). KCC2a and KCC2b isoforms differ from their intracellular amino-terminal domain with KCC2a having a 23 amino acids longer sequence bearing a SPAK-binding domain (blue). Other regulatory sequences of KCC2 are located within the large intracellular carboxy-terminal domain (CTD), such as protein kinase C (PKC) phosphorylation sites (Serine S728, T787, S940 and S1034), Src family kinase phosphorylation sites (Tyrosine Y903, Y1087) and WNK-SPAK-OSR1 kinases (T906, T1007). Other regulatory sequences are present on this region: the ISO domain (pink) allowing for KCC2 activity under isotonic conditions, and protein associated with Myc (PAM; yellow), Proline/E/S/T (PEST; purple), SPAK (blue) and adaptor protein-2 (AP2; orange) binding sequences. Note that KCC2 activators staurosporine and $\mathrm{N}$-ethylmaleimide (NEM) act by controlling (de)phosphorylation of series of residues (brown).

TABLE 1 | Key regulatory sites and sequences on KCC2.

\section{Site}

Protein Associated with Myc (PAM)

LVLLNMPGPPRNRNGDENYM

PEST sequence

ISO domain

PSPVSSEGIKDFFSM

AP-2 interaction domain

LLRLEE

SPAK-OSR1 interaction domain

RFTV

Cysteines

$\mathrm{N}$-Glycosylation sites

Tyrosines

\section{Localization}

1069-1088

PEST-1: 949-966

PEST-2: 974-1002

1021-1035

657-662

$4-7$

287-302-322-331

283-291-310-328-338-339

34-787-906-1007

34, 999, 1009

34,1009

728-940-1,034

$31,913,932,988$

25, 26, 937, 1022, 1025, 1026

\section{References}

Garbarini and Delpire (2008)

Mercado et al. (2006)

Mercado et al. (2006)

Zhao et al. (2008)

Piechotta et al. (2002)

Hartmann et al. (2010)

Agez et al. (2017)

Rinehart et al. (2009), de Los Heros et al. (2014), Weber et al. (2014) and Cordshagen et al. (2018)

Lee et al. (2007), Weber et al. (2014) and Cordshagen et al. (2018)

Positions are shown relative to the human KCC2b protein. 
KCC4 studies, N-linked glycosylation in the KCC2 LEL was proposed to be crucial for the membrane targeting of KCC2 (Hartmann and Nothwang, 2015). Six glycosylation sites on KCC2 were subsequently identified (Agez et al., 2017). Three human KCC2 mutations associated with severe early-onset epileptic encephalopathy showed reduced protein glycosylation and cell surface KCC2 (Stödberg et al., 2015), implicating KCC2 glycosylation in the control of its membrane expression. In addition, four highly conserved cysteine residues within the LEL were shown to be important for KCC2 activity but not membrane expression in HEK 293 cells probably due to their implication in inter- or intra-molecular di-sulfide bonds and correct protein folding (Hartmann et al., 2010).

The KCC2 CTD contains most of the KCC2 regulatory sequences. Complete truncation of the CTD reduces membrane expression of KCC1, 2 and 3 in Xenopus laevis oocytes and HEK 293 cells (Payne, 1997; Casula et al., 2001; Howard et al., 2002). Using live-cell surface labeling, Friedel et al. (2017) recently showed in cultured hippocampal neurons that KCC2 CTD is dispensable for membrane delivery of the transporter but is required for its membrane stabilization. Consistent with these observations, truncation of the KCC2 CTD by the $\mathrm{Ca}^{2+}$-dependent protease calpain at an unknown site leads to the internalization and lysosomal degradation of KCC2 in rat brain slices (Puskarjov et al., 2012). Moreover, the interaction of KCC2 CTD with the clathrin-binding adaptor protein-2 (AP-2) via a di-leucine motif induces a constitutive, dynamin-dependent and clathrin-mediated endocytosis of KCC2 in HEK 293 cells (Zhao et al., 2008). The CTD also hosts the majority of KCC2 phosphorylation residues (Figure 2) which influence KCC2 membrane stability and thereby function through regulation of the transporter's lateral diffusion, oligomerization, clustering, and endocytosis (see below).

In contrast to other KCCs, KCC2 is constitutively active under isotonic conditions (Payne, 1997). A short sequence called ISO domain $(1,022-1,037)$ located in the CTD has been shown to be responsible for this specific feature in Xenopus oocytes and hippocampal neurons (Mercado et al., 2006; Acton et al., 2012). Thus, replacement of this sequence by the corresponding KCC4 amino acids abolished constitutive KCC2 activity (Acton et al., 2012). Interestingly, KCC2 transporters lacking the ISO domain can still be activated under hypotonic conditions, indicating that two distinct domains are involved in KCC2 activation under isotonic vs. hypotonic conditions.

\section{TEMPORAL AND SPATIAL EXPRESSION PATTERN OF KCC2}

KCC2 expression can be observed throughout the central nervous system (CNS) including spinal cord (Hübner et al., 2001), thalamus (Barthó et al., 2004), cerebellum (Williams et al., 1999), hippocampus (Rivera et al., 1999), cortical structures (Gulyás et al., 2001) and the auditory brainstem (Blaesse et al., 2006). Although KCC2 expression is very broad in the CNS, the reversal potential of $\mathrm{GABA}_{\mathrm{A}} \mathrm{R}$-mediated currents $\left(\mathrm{E}_{\mathrm{GABA}}\right)$ varies among neuronal populations and brain structures (Chavas and
Marty, 2003; Watanabe and Fukuda, 2015). These differences are thought to reflect changes in CCC expression and function.

\section{Developmental Expression}

Developmental upregulation of KCC2 expression has been described in different systems including human (Dzhala et al., 2005; Sedmak et al., 2016), mouse (Hübner et al., 2001), rat (Gulyás et al., 2001), zebrafish (Zhang et al., 2010), C. elegans (Tanis et al., 2009) and other species (for review Blaesse et al., 2009; Kaila et al., 2014). The KCC2 expression profile is well correlated with the sequential maturation of different brain regions (Watanabe and Fukuda, 2015), and follows the rostrocaudal axis of neuronal maturation (Li et al., 2002; Stein et al., 2004). Interestingly only the KCC2b isoform is developmentally upregulated, while KCC2a expression remains constant over brain maturation (Yeo et al., 2009). In the neonatal mouse brainstem KCC2a therefore contributes to about $20 \%-50 \%$ of the total KCC2 mRNA expression, while in the mature cortex its contribution decreases down to 5\%-10\% (Uvarov et al., 2009). KCC2a is expressed in the basal forebrain, hypothalamus and spinal cord, but is absent from the hippocampus (Markkanen et al., 2014). In contrast to full KCC2 knockout mice, which die at birth due to respiratory failure (Hübner et al., 2001), KCC2b knockout mice are viable until postnatal age 15 (P15; Woo et al., 2002). This suggests that both KCC2a and KCC2b isoforms are essential but contribute differentially to brain development and the establishment of inhibitory neurotransmission. Indeed, Dubois et al. (2018) recently showed a transient role of KCC2a at birth controlling the pontine neuromodulation of the respiratory motor circuits.

\section{Subcellular Expression}

At the cellular level, KCC2 expression can be found in the somatodendritic plasma membrane in most brain regions, such as cerebellum (Williams et al., 1999), hippocampus (Rivera et al., 1999; Gulyás et al., 2001) or cortex (Szabadics et al., 2006). KCC2 membrane expression is enriched near inhibitory and excitatory synapses and in spine heads of hippocampal neurons (Gulyás et al., 2001; Hübner et al., 2001; Blaesse et al., 2006; Gauvain et al., 2011; Chamma et al., 2012). At the presynaptic level, only developing photoreceptor cells (Zhang et al., 2006) and retinal bipolar cells (Vardi et al., 2000) exhibit KCC2 expression. Axonal exclusion of KCC2 from CNS axons, including axon initial segment (Williams et al., 1999; Hübner et al., 2001; Chamma et al., 2012), leads to higher $\left[\mathrm{Cl}^{-}\right]_{\mathrm{i}}$ in axons than in the somatodendritic compartment (Price and Trussell, 2006). As a consequence, activation of $\mathrm{GABA}_{\mathrm{A}} \mathrm{R}$ by GABA spillover or axo-axonic GABAergic synapses leads to increased axonal excitability (Stell et al., 2007; Ruiz et al., 2010; Pugh and Jahr, 2011, 2013; Stell, 2011).

Association of KCC2 with the plasma membrane increases during neuronal maturation. Hence, immature neurons show brighter intracellular labeling than mature neurons (Gulyás et al., 2001; Szabadics et al., 2006) and KCC2 forms clusters at the surface of mature neurons (Gulyás et al., 2001; Hübner et al., 2001; Barthó et al., 2004; Watanabe et al., 2009; Chamma et al., 2012, 2013; Heubl et al., 2017). In primary 
cultures of hippocampal neurons, KCC2 protein expression can be observed already at 3 days in vitro (div) in the soma, while the somatodendritic labeling peaks only at div 15 (Ludwig et al., 2003).

Markkanen and colleagues were the first to compare the subcellular distribution of the two KCC2 isoforms, KCC2a and KCC2b, in the deep cerebellar nucleus, the pons and the medulla, in hippocampal cultured neurons (Markkanen et al., 2014, 2017). The authors showed that in these neurons, KCC2a and KCC2b only partly colocalize and that the two isoforms are not localized in the same subcellular compartments in mature neurons (with stronger labeling of $\mathrm{KCC} 2 \mathrm{~b}$ on the soma and plasma membrane in general). The functional consequence of this distinct isoform localization however remains unclear.

\section{MOLECULAR AND CELLULAR MECHANISMS OF REGULATION OF KCC2}

KCC2 is regulated at the transcriptional and post-transcriptional level (e.g., through phosphorylation/dephosphorylation of key residues) which in turn influence its cellular trafficking (cell surface delivery, membrane diffusion-trapping, clustering, surface removal and intracellular degradation).

\section{Transcriptional Regulation of KCC2}

The neuron-specific KCC2 expression pattern is tightly regulated by transcription factors and neuron-restrictive silencing elements (NRSE) in the KCC2 gene Slc12a5 (Karadsheh and Delpire, 2001; Uvarov et al., 2005, 2006; Yeo et al., 2009). Two NRSE sequences were found in intron 1 of the Slc12a5 gene (Karadsheh and Delpire, 2001) and in the upstream regulatory region (Yeo et al., 2009). Binding of each of the restrictive elements to a neuron-restrictive silencing factor/repressorelement transcription factor (NRSF/REST) is sufficient to repress gene transcription (Yeo et al., 2009). In addition to these negative regulatory elements, two positive regulatory regions in the Slc12a5 gene have been reported. Binding of the neuron specific transcription factor Egr4 (early growth response 4) to the Egr (early growth response) binding site activates KCC2 transcription (Uvarov et al., 2006). Similarly, Markkanen et al. (2008) found that binding of upstream stimulation factors, USF1 and 2, to an enhancer box (E-box) activates KCC2 expression.

The brain-derived neurotrophic factor (BDNF) has been shown to modulate KCC2 expression (Poo, 2001; Rivera et al., 2002; Aguado et al., 2003; Gottmann et al., 2009; Watanabe and Fukuda, 2015). While BDNF promotes KCC2 expression in immature neurons, exposure of mature CA1 pyramidal neurons to BDNF leads to decreased chloride extrusion (Rivera et al., 2004). Conversely, GABA increases BDNF expression in immature hippocampal and cerebrocortical neurons but not in mature hippocampal neurons, indicating a synergistic effect of GABAergic maturation and BDNF (Berninger et al., 1995; Kuczewski et al., 2011; Porcher et al., 2011). However, BDNF depletion (as shown in BDNF knockout mice) does not affect the developmental upregulation of KCC2 expression and function (Puskarjov et al., 2015). These results contrast with the reduced hippocampal KCC2 expression observed in TrkB knockout mice (Carmona et al., 2006) and the BDNF-induced increase in KCC2 mRNA expression in immature hippocampal neurons (Aguado et al., 2003; Rivera et al., 2004; Ludwig et al., 2011). Altogether, these results support a role of BDNF and TrkB in the developmental upregulation of KCC2.

Other trophic factors such as insulin-like growth factor 1 (Kelsch et al., 2001) and neurturin (Ludwig et al., 2011) have been implicated in the regulation of KCC2 expression. These data indicate that several signals control KCC2 expression and interact to increase KCC2 expression during neuronal development. The correlation of synaptic maturation with KCC2 upregulation therefore suggests their reciprocal influence.

\section{Posttranslational Regulatory Mechanisms}

Ion-transport activity of KCC2 does not only depend on KCC2 expression levels but also on the abundance and activity of numerous other proteins such as scaffolding proteins, cytoskeleton interactors/regulators, kinases and phosphatases that regulate its cellular trafficking.

\section{Exocytosis}

Consistent with the developmental switch of GABA/glycine neurotransmission, translocation of KCC2 from the cytoplasm to the plasma membrane indicates that exocytosis contributes to the control of KCC2-mediated chloride extrusion. Dynamic visualization of membrane insertion or internalization using recombinant proteins linked to $\mathrm{pH}$-sensitive fluorophores helped to determine exocytosis-endocytosis trafficking of several neurotransmitter receptors (Petrini et al., 2014; Zhang et al., 2015). Since the NTD and CTD of KCC2 are both cytosolic, a pH-sensitive pHluorin tag was inserted in the second or third extracellular loop of the transporter (Friedel et al., 2015, 2017). Insertion of the tag loop of the transporter did not perturb the function of the protein and therefore this construct constitutes a useful tool to study KCC2 trafficking (Friedel et al., 2017). The expression of pHluorin-tagged KCC2 mutants with deletions of the $\mathrm{N}$ terminal $(\triangle \mathrm{NTD})$ or $\mathrm{C}$ terminal $(\triangle \mathrm{CTD})$ domain and the use of live-cell surface immunolabeling of heterologous cells or cultured hippocampal neurons revealed that the NTD is essential for KCC2 plasma membrane delivery whereas the CTD is critical to its membrane stability (Friedel et al., 2017).

Recently, insights into the regulatory mechanisms of KCC2 exocytosis were obtained as transforming growth factor $\beta 2$ (TGF- $\beta 2$ ) was shown to mediate translocation of KCC2 from intracellular pools to the plasma membrane in developing and mature hippocampal neurons (Roussa et al., 2016). The mechanism for TGF- $\beta 2$-mediated KCC2 membrane translocation involves the Ras-associated binding protein $11 \mathrm{~b}$ (Rab11b). KCC2-Rab11b interaction was recently confirmed in a native KCC2 interactome study (Mahadevan et al., 2017).

\section{Oligomerization}

Multimeric assembly has been demonstrated for a large number of members of the CCC family (Moore-Hoon and Turner, 2000; Casula et al., 2001, 2009; Starremans et al., 2003; Blaesse et al., 2006; Simard et al., 2007; Warmuth et al., 2009). KCC2 was shown to form KCC2a and KCC2b homo-dimers, 
as well as KCC2a-KCC2b, KCC2-KCC4 and KCC2-NKCC1 hetero-dimers, in biochemical assays from neuronal and heterologous cell lysates (Blaesse et al., 2006; Simard et al., 2007; Uvarov et al., 2009).

There are discrepancies in the literature regarding the proportions of KCC2 monomers, dimers and higher-order oligomers in neurons. Blaesse et al. (2006) showed that an increase of KCC2 oligomers parallels transporter activation in the developing brainstem (between P2 and P30) whereas Uvarov et al. (2009) found oligomerization already at P2 in various brain regions. Mahadevan et al. $(2014,2017)$ using native PAGE reported that KCC2 form monomers, dimers as well as higher molecular mass complexes. However, using similar approaches, Agez et al. (2017) detected KCC2 monomers and dimers but not higher-order oligomers. These discrepancies may arise from differences in both experimental assays (native perfluorooctanoate-PAGE vs. 3\%-8\% Tris-acetate NuPAGE; Blaesse et al., 2006; Uvarov et al., 2009) as well as detergents used for sample preparation (CALX-R3 vs. C12E9; Agez et al., 2017; Mahadevan et al., 2017). These limitations also apply to SDS-PAGE studies, as differences in sample preparation influence the proportion of KCC2 dimer-like complexes (Medina et al., 2014). In conclusion, it is not possible to compare the relative abundance of KCC2 monomers, dimers and higherorder oligomers between studies.

The oligomerization domain has not been identified to date. However, several studies showed self-assembling capability for the CTD of NKCC1 and an Archean CCC (Simard et al., 2004; Warmuth et al., 2009) and decreased oligomerization of KCCs truncated on the C-terminus, or mutated on tyrosine residue 1087 (Simard et al., 2007; Watanabe et al., 2009). This observation suggests that KCC2 CTD might be involved in the assembly of the transporters as observed in Xenopus oocytes and hippocampal cultures (Simard et al., 2007; Watanabe et al., 2009). Whether the monomeric KCC2 is active remains unclear. Several studies reported a correlation between decreased KCC2 oligomerization and reduced transport activity (Watanabe et al., 2009; Mahadevan et al., 2014). For instance, neuropilin and tolloid like-2 (Neto-2) assemble with the oligomeric forms of KCC2 and this interaction increases KCC2-mediated $\mathrm{Cl}^{-}$extrusion in cultured hippocampal neurons (Ivakine et al., 2013). Similarly, the kainate receptor GluK2 subunit interacts with KCC2 and is critical to KCC2 oligomerization, surface expression and ion-transport function in hippocampal neurons (Mahadevan et al., 2014; Pressey et al., 2017). However, since changes in KCC2 oligomerization and surface expression occur in parallel, these observations do not demonstrate a causal link between $\mathrm{KCC} 2$ oligomerization and $\mathrm{Cl}^{-}$transport.

\section{Clustering}

KCC2 forms clusters in the neuronal plasma membrane (Gulyás et al., 2001; Hübner et al., 2001; Barthó et al., 2004; Watanabe et al., 2009; Chamma et al., 2012, 2013; Heubl et al., 2017). Interestingly the majority of KCC2 clusters are found at excitatory and inhibitory synapses in hippocampal cultures, without preferential accumulation at one type of synapses (Chamma et al., 2013). Ultrastructural studies indicate that
KCC2 accumulates at the periphery of synapses in dendritic spines as well as on the dendritic shaft (Gulyás et al., 2001; Báldi et al., 2010).

KCC2 clustering could help to localize and/or stabilize transporters in sub-membrane compartments (e.g., near excitatory and inhibitory synapses), and to form a barrier in dendritic spines surrounding glutamatergic postsynaptic densities. Moreover, KCC2 clustering has been proposed to regulate the cotransporter function. Watanabe et al. (2009) showed that inhibition of tyrosine phosphorylation or deletion of a nearby region $(\Delta 1089-1116)$ both lead to disruption of KCC2 clustering and transport activity without any change in the neuronal membrane pool. This suggests that the KCC2 CTD is involved in cluster formation and that clustering and function of the transporter are tightly correlated. Overexpression of the CTD on the other hand causes a decrease in KCC2 cluster size with no alteration of cluster density or chloride transport in hippocampal neurons (Chamma et al., 2013), suggesting KCC2 clustering does not rely exclusively on its CTD binding to the cytoskeleton. Association of KCC2 with lipid rafts was proposed to influence KCC2 clustering. Watanabe et al. (2009) observed that association with lipid rafts increases KCC2 clustering and function in neuronal cultures, while Hartmann et al. (2009) found larger clusters and enhanced transport activity after disruption of lipid rafts. The later study, however, was performed in HEK 293 cells and showed an overall increase in KCC2 surface expression. It therefore remains unclear how clustering of KCC2 in lipid rafts modifies its transport activity in neurons.

\section{Lateral Diffusion}

Lateral diffusion is a key mechanism controlling rapid activitydependent changes in neurotransmitter receptor number (and therefore clustering) at synapses, a phenomenon underlying the tuning of synaptic transmission and plasticity (Choquet and Triller, 2013). Receptors constantly alternate between periods of free Brownian-type motion outside synapses and constrained diffusion at synapses. They are captured and confined at synapses by transient interactions with postsynaptic scaffolding molecules that anchor them to the underlying cytoskeleton. A reduced density of scaffolding proteins at synapses and/or a weakening of receptor-scaffold interactions increases the escape of receptors from synapses and thereby clustering and synapse efficacy. Since KCC2 is similarly clustered near excitatory and inhibitory synapses, we addressed the role of lateral diffusion on KCC2 subcellular distribution and function. This was analyzed using Quantum-based Single Particle Tracking (QDSPT) in hippocampal cultures (Chamma et al., 2012, 2013; Heubl et al., 2017).

These experiments showed that KCC2 displays free Brownian-type motion outside clusters while it is slowed down and confined within clusters located near excitatory and inhibitory synapses (Chamma et al., 2012, 2013). However, KCC2 escapes clusters faster near inhibitory synapses than excitatory synapses, reflecting stronger molecular constraints at excitatory synapses. Further investigations suggested specific tethering of KCC2 near excitatory synapses through actin- 
binding of the CTD of KCC2 via the actin binding protein $4.1 \mathrm{~N}$, whereas KCC2 is confined at inhibitory synapses by a distinct mechanism (Chamma et al., 2013). Therefore, KCC2 undergoes a diffusion-trap mechanism similar to neurotransmitter receptors.

KCC2 lateral diffusion is rapidly tuned by activity. Enhancing glutamatergic excitation or reducing GABAergic inhibition both increased KCC2 membrane diffusion (Chamma et al., 2013; Heubl et al., 2017) through reduced phosphorylation of S940 and increased phosphorylation of T906/1007, respectively. Changes in transporter diffusion were accompanied by cluster dispersion and increased membrane turnover of the transporter. Therefore, we propose that different subpopulations of transporters exist in the plasma membrane: freely moving KCC2 outside clusters and transporters confined in clusters in the vicinity of synapses. These two pools of transporters are in a dynamic equilibrium that can vary in response to changes in synaptic activity. The extracluster pool of transporters can be considered as a reserve pool in equilibrium with the perisynaptic pool. Transitions between these compartments by lateral diffusion may then participate in the fine tuning of synapses in response to local fluctuations of synaptic activity (Figure 3). Since changes in KCC2 mobility occur within tens of seconds (Heubl et al., 2017), lateral diffusion is probably the first cellular mechanism modulating the transporter membrane stability. This may represent a rapid mechanism for adapting $\mathrm{Cl}$ - homeostasis to changes in synaptic activity.

\section{Endocytosis}

While activity-dependent KCC2 endocytosis was shown to rapidly decrease its neuronal membrane pool (Lee et al., 2011; Chamma et al., 2013; Heubl et al., 2017), KCC2 turn-over rate under basal conditions is controversial. Two studies showed a high turn-over rate (of about $20 \mathrm{~min}$ ) of the transporter in neuronal cultures (Lee et al., 2010) and rat hippocampal slices (Rivera et al., 2004). In contrast, Puskarjov et al. (2012) observed no change in KCC2 membrane pool in hippocampal slices after $4 \mathrm{~h}$ inhibition of protein synthesis (by cycloheximide) or degradation (by leupeptin). Although the authors concluded that KCC2 has a rather low turnover, what they were testing in this study was the lifetime of the transporter. Once KCC2 is synthesized and inserted in the membrane, it undergoes several cycles of endocytosis and exocytosis until final degradation. The lifetime of the transporter therefore seems to be $>4 \mathrm{~h}$ whereas KCC2 turn-over rate at the membrane is in the range of $20-30 \mathrm{~min}$.

Lee et al. (2010) reported increased surface expression of endogenous KCC2 in hippocampal cultured neurons after a $45 \mathrm{~min}$ exposure to dynasore, a cell-permeable inhibitor of dynamin. Using co-immunoprecipitation experiments, Zhao et al. (2008) showed that endogenous KCC2 interacts with the clathrin-binding AP2, suggesting that KCC2 internalization may be controlled by the clathrin-mediated endocytic pathway. Then, they identified in HEK293 cells a constitutive, non-canonical endocytic 657LLRLEE662 motif in the KCC2 CTD. Both di-leucine residues are required to mediate efficient transporter endocytosis but the L658 residue is the most important. The two glutamic acid residues downstream regulate the function of the di-leucine endocytic motif. This motif is highly conserved among KCC family members but not in NKCC1, NKCC2 or NCC proteins (Zhao et al., 2008). Furthermore, protein kinase C (PKC) and casein kinase substrate in neurons protein 1 (PACSIN1), which are involved in clathrin-mediated endocytosis and vesicle transport in neurons (Schael et al., 2013), were recently identified in a KCC2 interactome study (Mahadevan et al., 2017). Altogether these results suggest that KCC2 membrane retrieval may require AP2 and PACSIN1. PACSIN1 has been shown to regulate the activity-dependent AMPAR surface recycling in cerebellar neurons (Anggono et al., 2013; Widagdo et al., 2016). More work is now needed to test whether PACSIN1 plays a similar role in activity-dependent membrane recycling of KCC2.

However, regarding clathrin-dependence of KCC2 endocytosis, it is important to mention that the motif identified by Zhao et al. (2008) in an artificial overexpression system is non-canonical. Whether this motif plays a role in neurons and whether other regions on KCC2 are critical for internalization remains to be tested. Endocytosis of most transmembrane molecules involves post-translational modifications favoring interaction with the clathrin pathway that have not been clearly demonstrated for KCC2.

\section{Degradation}

Constitutively internalized transporters are not targeted for lysosomal degradation in HEK 293 cells (Zhao et al., 2008). Only upon increased glutamatergic activity does KCC2 undergo lysosomal degradation. This has been shown in spinal cord neurons following peripheral nerve injury (Zhou et al., 2012), in cultured hippocampal neurons and hippocampal slices upon application of the glutamate receptor agonist NMDA (Lee et al., 2011; Puskarjov et al., 2012) or interictal-like activity induced by $\mathrm{Mg}^{2+}$ depletion (Puskarjov et al., 2012). This process has been shown to require $\mathrm{Ca}^{2+}$-activated calpain cleavage of the KCC2 CTD (Puskarjov et al., 2012; Zhou et al., 2012). The exact location of the proteolytic cleavage site remains unknown. However, since it was proposed that KCC2 S940 dephosphorylation is a pre-requisite for calpain cleavage (Chamma et al., 2013), the calpain cleavage site may be positioned near the $\$ 940$ residue.

\section{Phospho-Regulation of KCC2}

Phosphorylation or dephosphorylation of KCC2 key tyrosine, serine or threonine residues tune KCC2 activity mainly by controlling its membrane stability. KCC2 stability and clustering at the plasma membrane is directly regulated via its CTD and notably Y1087 and Y903 residues in HEK 293 cells, GT1-7 cells and hippocampal neurons (Watanabe et al., 2009; Lee et al., 2010). Other pathways have also been identified, and their consequences on KCC2 membrane stability and function characterized (Lee et al., 2007; Rinehart et al., 2009; Heubl et al., 2017). Thus, PKC-dependent phosphorylation of KCC2 S940 was shown to increase the transporter membrane stabilization in HEK 293 cells and in hippocampal neurons (Lee et al., 2007). Interestingly, S940 phosphorylation and calpainmediated cleavage have been negatively correlated in cultured hippocampal neurons (Chamma et al., 2013). Studies in HEK 293 cells reported that T1007 phosphorylation is mediated by 


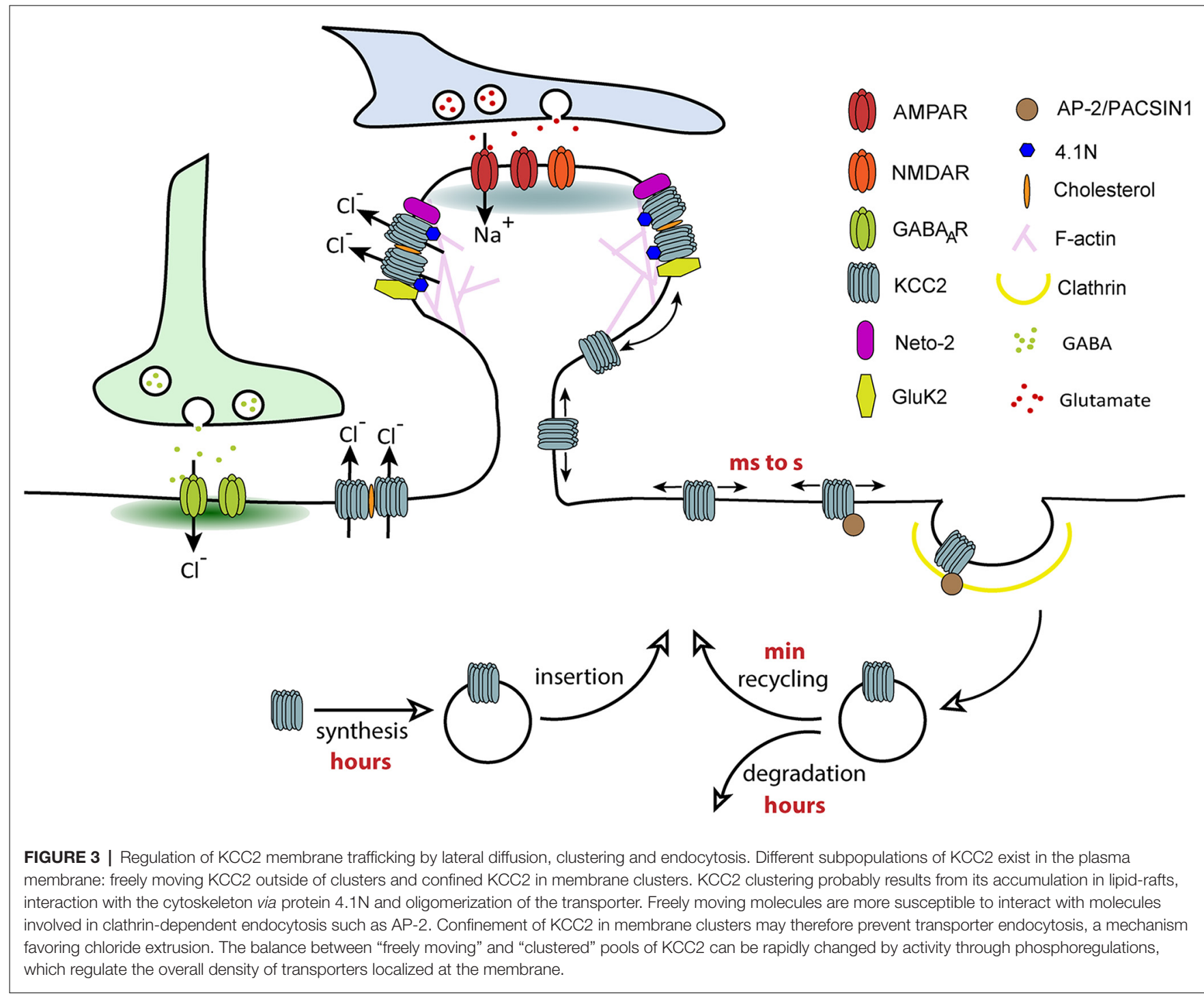

the serine/threonine kinase WNK1 [With No lysine (K) serinethreonine kinase 1] and its downstream effectors SPAK and OSR1 (Rinehart et al., 2009; de Los Heros et al., 2014). In contrast, T906 is not the target of WNK, SPAK or OSR1 in HEK 293 cells (de Los Heros et al., 2014; Zhang et al., 2016). The nature of the kinase phosphorylating T906 is still unknown (Zhang et al., 2016). The phosphorylation of T906 and T1007 keeps $\mathrm{E}_{\mathrm{GABA}}$ depolarized by decreasing the membrane pool of KCC2 both in immature neurons (Friedel et al., 2015) as well as in mature neurons in response to reduced $\mathrm{GABA}_{\mathrm{A}} \mathrm{R}$ activation (Heubl et al., 2017).

Other KCC2 phospho-sites have been identified in largescale phospho-proteomics studies: S31, T34, S913, S932, S988, T999, T1009 (according to human sequence; Cordshagen et al., 2018), and S25, S26, T34, S937, T1009, S1022, S1025 and S1026 (Weber et al., 2014). Several of these sites tune KCC2 transport activity but unlike Y1087, S940, T906 and T1007, this regulation does not involve changes in total or surface expression levels of the transporter. Phosphorylation of S932, T934, S937 and dephosphorylation of T1009 enhance KCC2 transport function in HEK 293 cells (Weber et al., 2014; Cordshagen et al., 2018). Moreover, two potent KCC2 activators, N-Ethylmaleimide (NEM) and staurosporine, differentially impact KCC2 transport activity through a complex mechanism of (de)phosphorylation of several of these phospho-sites (Weber et al., 2014; Conway et al., 2017; Cordshagen et al., 2018). Staurosporine triggers phosphorylation of S932 and dephosphorylation of T1009. The action of staurosporine on T1009 occurs indirectly by inhibiting a kinase while its effect on $\mathrm{S} 932$ would be due to an indirect inhibition of a phosphatase (Cordshagen et al., 2018). NEM increases the phosphorylation of S940 while it decreases the phosphorylation of T1007 (Conway et al., 2017). NEM is thought to dephosphorylate T1007 through the control of SPAK phosphorylation/activity (Conway et al., 2017). Furthermore, a complex regulatory mechanism of KCC2 activity by staurosporine and NEM likely involves a change in the transporter conformational state through the (de)phosphorylation of several, partly overlapping phospho-sites 
that include S31, T34 and T999 for staurosporine and S31, T34 and S932 for NEM (Cordshagen et al., 2018). The function of other phosphorylation sites (e.g., S25, S26, S1022, S1025 and S1026), however, remains unclear.

\section{REGULATION OF KCC2 CELLULAR TRAFFICKING BY NEURONAL ACTIVITY}

KCC2 mRNA, protein, and surface expression are known to be down-regulated under pathological conditions such as epilepsy or in experimental paradigms leading to enhanced excitatory activity, including long term potentiation (LTP; Wang et al., 2006a), rebound burst activity (Wang et al., 2006b), repetitive postsynaptic spiking activity (Fiumelli et al., 2005), coincident pre- and post- synaptic spiking (Woodin et al., 2003), NMDAR activation (Kitamura et al., 2008; Lee et al., 2011), and epileptiform activity (Reid et al., 2001; Rivera et al., 2004; Pathak et al., 2007; Li et al., 2008; Shimizu-Okabe et al., 2011). Most of these paradigms result in a depolarizing shift in $\mathrm{E}_{G A B A}$ due to a reduced KCC2 function and/or expression. Recently, KCC2 down-regulation was also observed in conditions of reduced GABAergic inhibition in mature neurons (Heubl et al., 2017). This raises questions about the cellular and molecular mechanisms controlling KCC2 activity. A mechanism has emerged that involves phospho-regulation of key KCC2 serine and threonine residues that in turn influence the membrane dynamics, clustering, endocytosis, recycling and/or degradation of the transporter (Lee et al., 2011; Puskarjov et al., 2012; Zhou et al., 2012; Chamma et al., 2013; Heubl et al., 2017).

\section{KCC2 Downregulation by Neuronal Excitation}

Under conditions of increased neuronal activity, KCC2 diffusion is rapidly increased leading to the dispersal of KCC2 clusters, transporter internalization, degradation and ultimately deficits in chloride transport (Lee et al., 2011; Puskarjov et al., 2012; Zhou et al., 2012; Chamma et al., 2013). These effects are mediated by NMDAR-dependent $\mathrm{Ca}^{2+}$ influx, $\mathrm{Ca}^{2+}$ induced protein phosphatase 1 (PP1) dephosphorylation of KCC2 S940 and $\mathrm{Ca}^{2+}$-activated calpain protease cleavage of KCC2 CTD. These data suggest that deficits in KCC2 activity induced by dephosphorylation of S940 may contribute to the development of status epilepticus in vivo. However, the importance of KCC2 S940 phospho-regulation in vivo remains unclear. KCC2 dephospho-mimetic S940 (S940A) knock-in mice display normal basal KCC2 expression levels and activity in the hippocampus and do not exhibit any overt behavioral abnormality. Only in conditions of hyperactivity, S940 mice showed increased lethality to kainate-induced seizures (Silayeva et al., 2015). It remains to be determined whether increased lethality reflects enhanced seizure severity due to altered chloride transport or a brainstem-mediated respiratory arrest. On the other hand, phosphorylation of T906/1007 inhibits KCC2 function (Rinehart et al., 2009). Mice in which T906/1007 phospho-dependent inactivation was prevented by mutation into alanine showed increased KCC2 transport function in basal conditions (Moore et al., 2018). This effect was not associated with increased KCC2 surface expression but seems to involve changes in the intrinsic properties of the transporter. Importantly, increased KCC2 function attenuates chemically-induced epileptiform activity in T906A/1007A mice, both in acute hippocampal slices and in vivo (Moore et al., 2018), suggesting that enhancing KCC2 activity through T906/1007 dephosphorylation may be an effective approach in epilepsy treatment.

\section{Implication in Glutamatergic Long-Term Potentiation}

LTP of glutamatergic synapses in cortical neurons relies mainly on NMDAR activation and $\mathrm{Ca}^{2+}$-dependent activation of intracellular kinases such as $\mathrm{Ca}^{2+} /$ calmodulin-dependent protein kinase II (CaMKII; Poncer, 2003). Consistent with the $\mathrm{Ca}^{2+}$ dependent regulation of the transporter, persistent $(>1 \mathrm{~h})$ KCC2 downregulation has been reported during hippocampal LTP (Wang et al., 2006a). Reduced KCC2 function was then hypothesized to dampen GABAergic transmission and to promote LTP at excitatory synapses (e.g., Ferando et al., 2016), although this hypothesis has not been tested experimentally. Instead, chronic KCC2 knockdown by RNA interference was shown to preclude LTP expression in hippocampal neurons (Chevy et al., 2015). This effect was independent of $\mathrm{Ca}^{2+}$ and CaMKII activation but instead involved the direct interaction of KCC2 with the Rac1-specific guanilyl exchange factor betaPIX. Loss of this interaction upon KCC2 suppression led to enhanced activation of Rac1 and its downstream effectors PAK1 and LIM kinase, which inhibit the actin-severing protein cofilin (Chevy et al., 2015; Llano et al., 2015). Thus, KCC2 suppression prevented actin depolymerization required for activity-driven AMPAR exocytosis during LTP (Gu et al., 2010). This effect however was observed upon chronic KCC2 knockdown. How acute downregulation of KCC2 upon physiologically induced LTP influences subsequent plasticity therefore remains to be tested.

\section{Regulation of KCC2 by GABAergic Inhibition}

Several studies have shown that KCC2 can be rapidly downregulated by enhanced neuronal activity and glutamatergic neurotransmission (see above). However, little was known until recently about the regulation of $\mathrm{KCC} 2$ by synaptic inhibition. A study by Woodin et al. (2003) reported that increased GABAergic transmission also leads to KCC2 downregulation. However, this study was carried out in immature neurons displaying mainly depolarizing excitatory $\mathrm{GABA}_{\mathrm{A}} \mathrm{R}$-mediating synaptic responses associated with activation of voltage-dependent $\mathrm{Ca}^{2+}$ channels (VDCCs) and intracellular $\mathrm{Ca}^{2+}$ signaling pathways (Woodin et al., 2003). Therefore, this study did not reveal regulation of KCC2 by synaptic inhibition per se but instead by excitatory GABAergic transmission.

A recent study from our group investigated the direct contribution of GABAergic inhibition in the regulation of $\mathrm{KCC} 2$ and chloride homeostasis in mature neurons (Heubl et al., 2017). In order to isolate the effect of GABAergic inhibition on KCC2 diffusion and membrane stability, we 


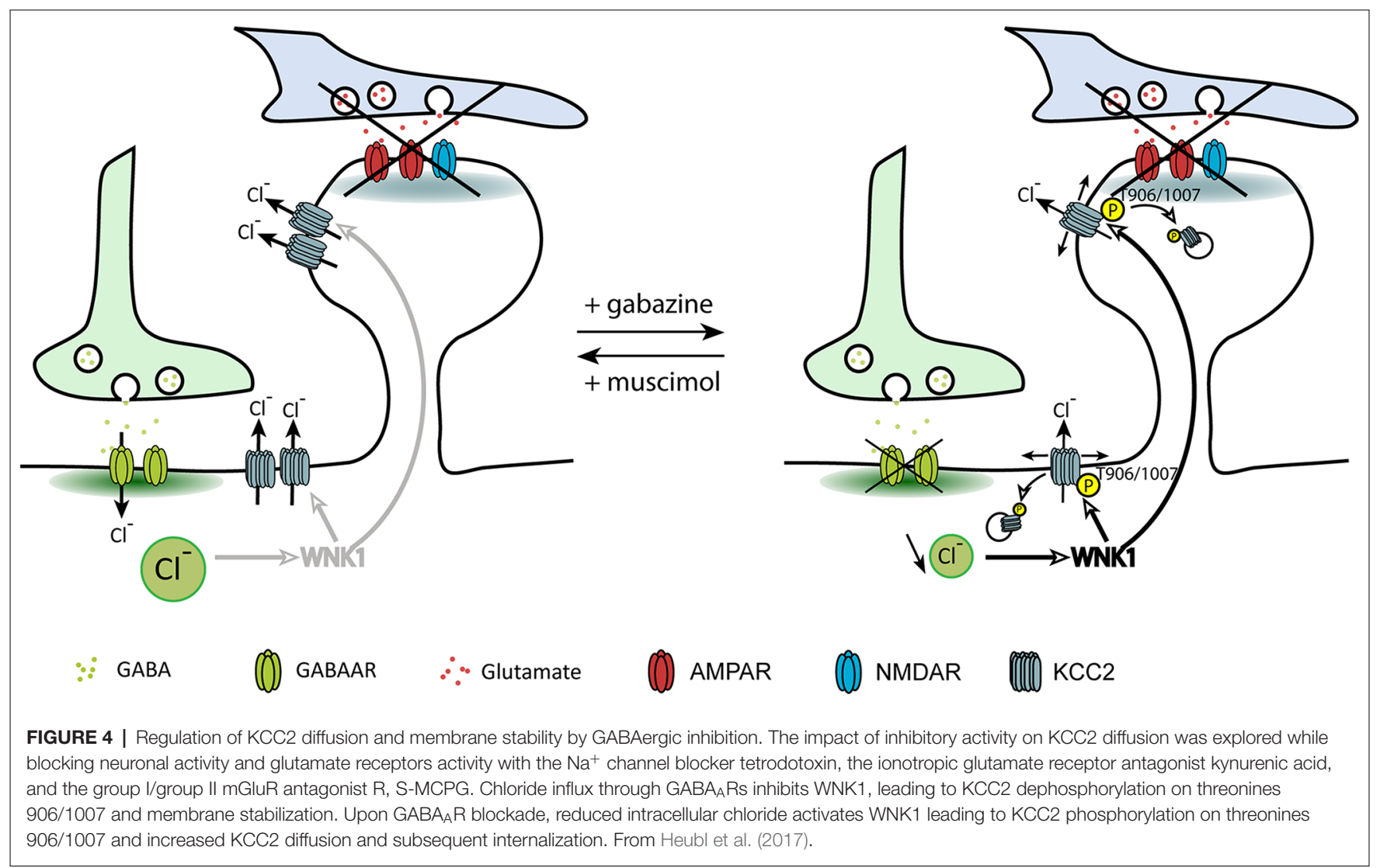

adjusted neuronal inhibition while blocking action potentials and glutamate receptors. In these conditions, increasing neuronal $\mathrm{GABA}_{\mathrm{A}} \mathrm{R}$-mediated synaptic inhibition with muscimol enhanced KCC2 diffusion constraints and membrane stability. On the other hand, $\mathrm{GABA}_{\mathrm{A}} \mathrm{R}$ activity blockade with gabazine increased KCC2 diffusion while reducing its membrane clustering and stability (Figure 4). Although these observations reflect the influence of bath application of $\mathrm{GABA}_{\mathrm{A}} \mathrm{R}$ agonists and antagonists on KCC2 membrane diffusion and stability, one could imagine that such regulation may also take place locally near GABAergic synapses.

The search for the signaling pathway underlying the $\mathrm{GABA}_{\mathrm{A}} \mathrm{R}$-dependent regulation of KCC2 demonstrated for the first time that $\mathrm{Cl}^{-}$acts as a genuine second intracellular messenger to rapidly tune inhibitory synaptic transmission (Heubl et al., 2017). Thus, lowering intracellular $\mathrm{Cl}^{-}$levels activates the $\mathrm{Cl}^{-}$-sensing WNK1 kinase which in turn phosphorylates and activates the SPAK and OSR1 kinases. Activated SPAK and OSR1 phosphorylate KCC2 T1007, leading to decreased KCC2 activity (Heubl et al., 2017). Conversely, increasing $\left[\mathrm{Cl}^{-}\right]_{\mathrm{i}}$ via photostimulation of halorhodopsin $\mathrm{eNpHR}$, the light-activated microbial chloride pump, significantly reduced diffusion coefficients and increased the confinement of KCC2 transporters. This mechanism would therefore allow neurons to locally increase or decrease their KCC2 pools to match GABAergic synaptic activity and subsequent need to extrude $\mathrm{Cl}^{-}$(Figure 5). We concluded that GABAergic inhibition in mature neurons tunes itself via rapid regulation of KCC2-mediated changes in intracellular $\mathrm{Cl}^{-}$levels. Since the effect of eNpHR was observed $10 \mathrm{~s}$ after light exposure, diffusion-trap of KCC2 appears to be a very rapid mechanism to control $\mathrm{Cl}^{-}$homeostasis in neurons.

However, the published values of the $\mathrm{Cl}^{-}$sensitivity of WNK1 measured in an in vitro kinase assay (Piala et al.,

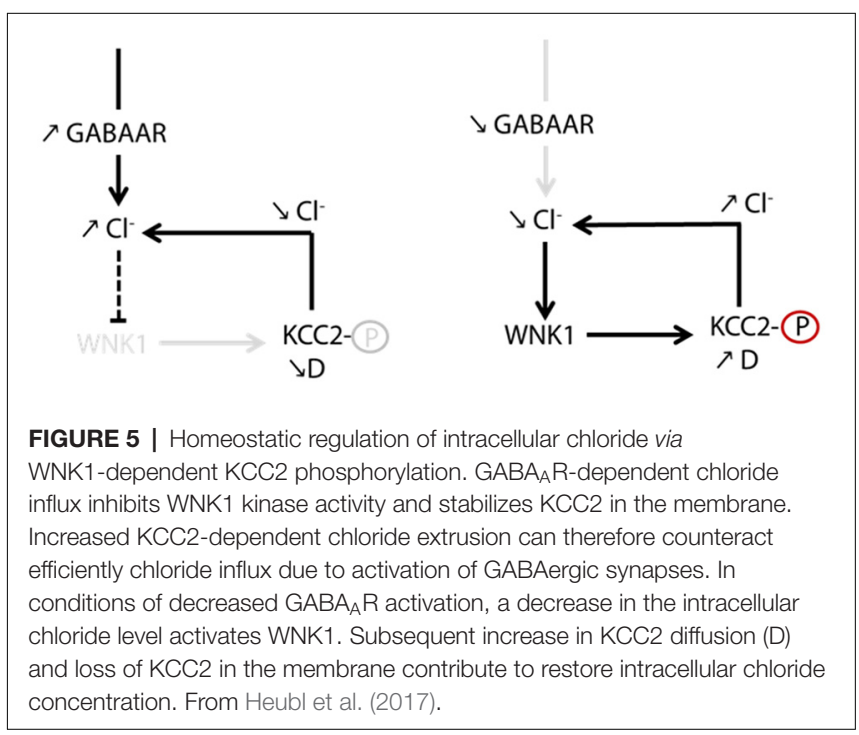



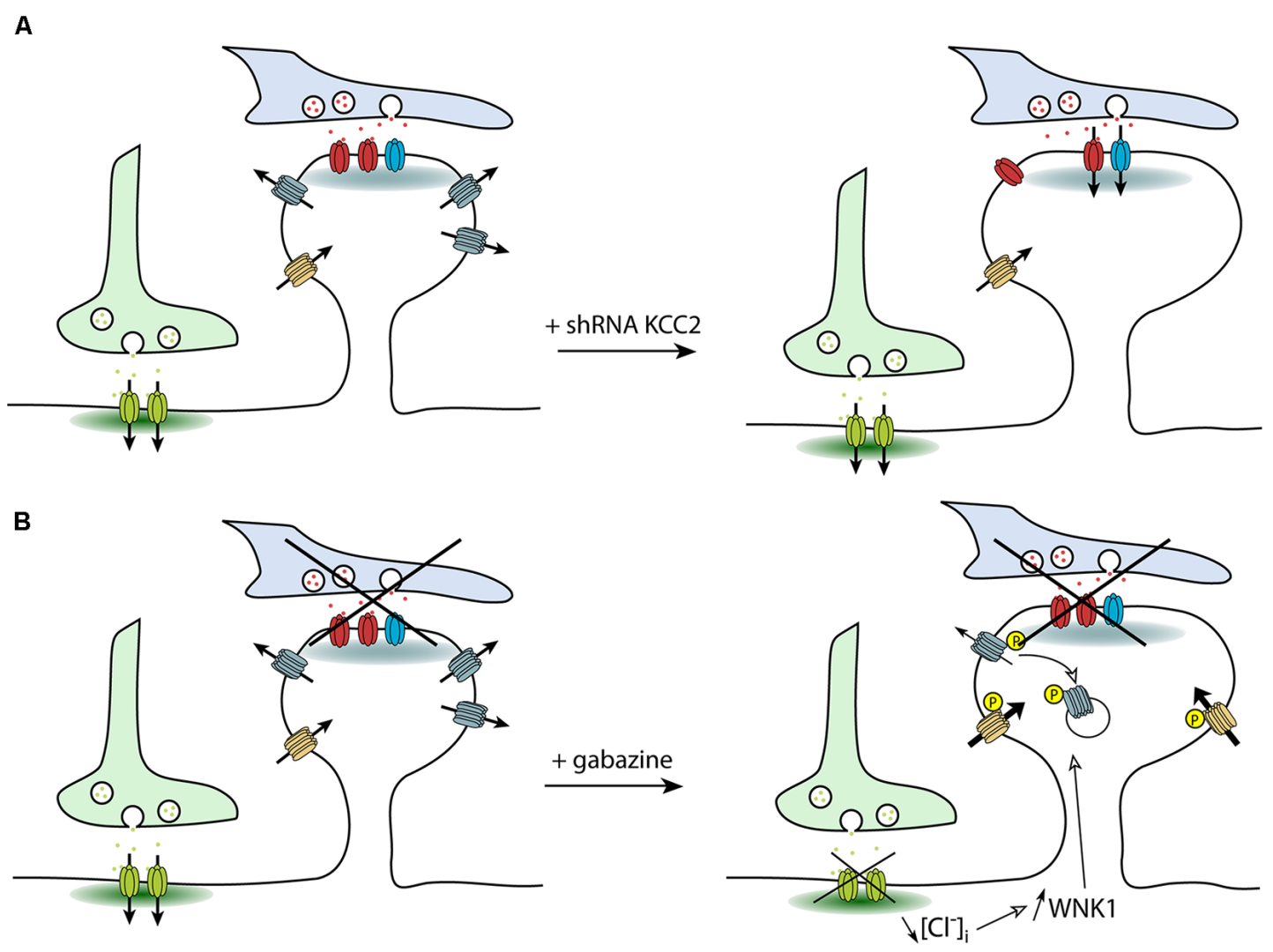

$\because$ GABA

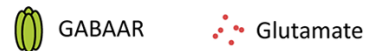

AMPAR

NMDAR

$\mathrm{KCC} 2$

(ciul $\mathrm{NKCC} 1$

FIGURE 6 | Regulation of dendritic spine head volume upon changes in KCC2 membrane expression. Arrows indicate water fluxes associated with the activity of secondary active transporters and ionotropic receptors. (A) Suppression of KCC2 expression leads to increased spine head volume due to the loss of KCC2-associated water extrusion. (B) Activation of WNK1 upon GABA $A_{A}$ blockade leads to KCC2 and NKCC1 phosphorylation and subsequent decrease and increase in the membrane stability of KCC2 and NKCC1, respectively. Increased water influx associated with NKCC1 activity cannot be counteracted by KCC2, leading to spine head swelling.

2014) cannot account for the activation of this signaling pathway upon $\mathrm{GABA}_{\mathrm{A}} \mathrm{R}$ activity changes in neurons (Heubl et al., 2017). Indeed, intracellular chloride levels in these cells are expected to be in the range of $5-10 \mathrm{mM}$ under control conditions, down to $4-6 \mathrm{mM}$ after $\mathrm{GABA}_{\mathrm{A}} \mathrm{R}$ blockade and up to $10-15 \mathrm{mM}$ upon $\mathrm{GABA}_{\mathrm{A}} \mathrm{R}$ activation. The IC50 of chloride was about $20 \mathrm{mM}$ for WNK1 autophosphorylation (Piala et al., 2014) and $100 \mathrm{mM}$ for phosphorylation of its target SPAK in an in vitro kinase assay (Terker et al., 2016). If transposable in situ, these values would suggest WNK1 would be constantly activated in neurons. Instead, we showed modulation of WNK1 activity even upon subtle intracellular chloride changes (Heubl et al., 2017). The chloride sensitivity of WNK1 in neurons remains to be determined. Additional mechanisms such as membrane translocation (Zagórska et al., 2007) or interaction with other ion-sensitive molecules could modulate the chloride sensitivity of WNK1 upon $\mathrm{GABA}_{\mathrm{A}} \mathrm{R}$ blockade. Further characterization of WNK1 localization and activity in neurons would therefore provide invaluable insights into how changes in osmolarity and ion concentration can tune its kinase activity.

This signaling pathway may also participate in the onset of pathological conditions. Indeed, a single subcutaneous injection of the $\mathrm{GABA}_{\mathrm{A}} \mathrm{R}$ antagonist pentylenetetrazole (PTZ) to elicit epileptic seizures in vivo increased WNK1, SPAK and OSR1 phosphorylation/activities and promoted KCC2 T906/1007 phosphorylation, which resulted in KCC2 inhibition in neuronal cells (Heubl et al., 2017). Interestingly, PTZ injection also increased NKCC1 T203/T207/T212 phosphorylation. Considering threonine phosphorylation was shown to have opposite effects on KCC2 vs. NKCC1 activity (McCormick and Ellison, 2011), the downregulation of the WNK/SPAK/OSR1 pathway could be a very efficient mechanism to adjust neuronal $\mathrm{Cl}^{-}$homeostasis in disorders associated with altered inhibition like epilepsy, schizophrenia, autism and neuropathic pain.

Since KCC2 S940 residue is crucial for the regulation of KCC2 transport activity (see above), one may wonder 
about the interplay between KCC2 T906/1007 and S940. KCC2 diffusion was increased upon gabazine application even when S940 was mutated to aspartate, indicating that threonine phosphorylation can destabilize KCC2 in the membrane independently of its S940 phospho-status (Heubl et al., 2017). On the other hand, NMDAR-dependent S940 dephosphorylation in neurons in which KCC2 T906/1007 were mutated into alanine also destabilizes KCC2 independently of the threonine phosphorylation status. Hence, the kinase pathways involved in KCC2 regulation by GABAergic inhibition and neuronal excitation appear to be largely independent.

\section{Impact at Glutamatergic Synapses}

Several studies showed that, in addition to its role in setting $\left[\mathrm{Cl}^{-}\right]_{\mathrm{i}}$ in mature neurons, KCC2 also influences spine head volume as well as the efficacy of glutamatergic neurotransmission (e.g., Gauvain et al., 2011; Chevy et al., 2015). KCC2-mediated spine head volume regulation may rely on water fluxes associated with ion transport, as demonstrated for KCC- (Zeuthen, 1991a,b) and NKCC-mediated transport in epithelial cells (Hamann et al., 2005). Instead, the effect of KCC2 on glutamatergic transmission was shown to depend on its interaction with actin-related proteins (Gauvain et al., 2011). Thirty minutes of $\mathrm{GABA}_{\mathrm{A}} \mathrm{R}$ blockade with gabazine also induced dendritic spine swelling while $\mathrm{GABA}_{\mathrm{A}} \mathrm{R}$ activation with muscimol had no effect on dendritic spines (Heubl et al., 2017). The effect of gabazine is reminiscent of what was observed upon chronic KCC2 knockdown or pharmacological blockade. Spine swelling upon KCC2 blockade may thus result from ion and water influx associated with ionotropic receptor activation. Under basal activity, the number of opened receptors is low in hippocampal cultures, with spontaneous EPSP frequency ranging 20-50 Hz. However, gabazine-induced spine swelling occurred on a much faster time scale than with ionotropic glutamate receptors blockade (Gauvain et al., 2011; Heubl et al., 2017). Another mechanism could therefore be at play in the gabazine effect. WNK kinases regulate KCC2 and NKCC1 in opposite directions. Activation of WNK1 in conditions of reduced neuronal inhibition possibly leads to KCC2 removal from the plasma membrane while in the meantime NKCC1 is stabilized at the membrane (Vitari et al., 2006; McCormick and Ellison, 2011). Therefore, spine head swelling observed upon gabazine application may primarily involve increased NKCC1 membrane stabilization and water influx (Zeuthen and Macaulay, 2012). NKCC1 being very efficient in mediating water influx, this might explain the rapidity of the gabazine effect on dendritic spines as compared to that observed upon KCC2 blockade only (Figure 6). It would be interesting to directly test NKCC1 involvement in spine swelling upon gabazine application, for instance using the NKCC1 blocker bumetanide.

KCC2 knockdown leads to actin reorganization in spine heads (Chevy et al., 2015). Thus, reduced KCC2 content at the plasma membrane potentially weakens the molecular barrier formed by KCC2 in dendritic spines. This could in turn increase AMPAR escape from spines and reduce the efficacy of glutamatergic synapses as shown upon KCC2 knockdown (Gauvain et al., 2011). Therefore, we predict that $\mathrm{KCC} 2$ membrane removal upon reduced $\mathrm{GABA}_{\mathrm{A}} \mathrm{R}$ activity may act to homeostatically adjust GABAergic and glutamatergic synaptic transmission.

\section{Implication in Energy Loss}

The regulation of KCC2 may not only permit a rapid reaction to changes in $\left[\mathrm{Cl}^{-}\right]_{\mathrm{i}}$ but also preserve energy consumption. Thus, the loss of KCC2 in conditions of decreased $\mathrm{GABA}_{\mathrm{A}} \mathrm{R}$ dependent $\mathrm{Cl}^{-}$influx would maintain membrane KCC2 at minimal levels required to keep $\mathrm{E}_{\mathrm{GABA}}$ hyperpolarized. Indeed, for every $\mathrm{Cl}^{-}$ion extruded by KCC2, the transporter uses the energy of the electrochemical gradient of one potassium ion. The $\mathrm{Na}^{+} / \mathrm{K}^{+}$ATPase that generates the potassium transmembrane gradient is the main energy consumer in the brain (Buzsáki et al., 2007; Harris et al., 2012; de Lores Arnaiz and Ordieres, 2014). Even though the highest energetic cost of the $\mathrm{Na}^{+} / \mathrm{K}^{+}$ATPase is used to restore transmembrane potential upon action potential discharge (Harris et al., 2012; Howarth et al., 2012), maintaining low $\left[\mathrm{Cl}^{-}\right]_{\mathrm{i}}$ is associated with high metabolic cost (Kaila et al., 2014). Kaila et al. (2014) raising the hypothesis that "the downregulation of KCC2 following neuronal trauma may be part of a general adaptive cellular response that facilitates neuronal survival by reducing the energetic costs that are needed to preserve low $\left[\mathrm{Cl}^{-}\right]_{\mathrm{i}}$ ". Under physiological conditions, rapid redistribution of $\mathrm{KCC} 2$ in the membrane could allow neurons to save energy by keeping surface KCC2 molecules at the minimum required density.

In conclusion, normal and pathological excitatory and inhibitory activities rapidly tune KCC2 function at both inhibitory and excitatory synapses. This regulation occurs through phosphorylation-induced changes in KCC2 membrane diffusion, clustering, endocytosis, recycling or degradation. Although alterations in excitatory and inhibitory signaling might have similar effects on KCC2 cellular trafficking and function, the underlying molecular mechanisms are distinct and involve $\mathrm{Ca}^{2+}$ vs. $\mathrm{Cl}^{-}$signaling cascades and key serine and threonine KCC2 residues. The recent discovery of activity-dependent regulation of KCC2 by the $\mathrm{Cl}^{-}$-dependent WNK/SPAK/OSR1 signaling pathway is of particular interest in the pathology since it controls simultaneously KCC2 and NKCC1 in opposite directions. Further investigation will tell whether targeting this signaling pathway efficiently restores chloride homeostasis and synaptic inhibition in epilepsy, neuropathic pain and various neuropsychiatric disorders.

\section{AUTHOR CONTRIBUTIONS}

SL supervised the writing of the review and corrected the manuscript. JP gave advice. EC and $\mathrm{MH}$ participated equally in the writing of the review and ES wrote sub-sections of the manuscript.

\section{FUNDING}

This work was supported by Fondation Française pour la Recherche sur l'Épilepsie, Fédération pour la Recherche sur le Cerveau and Fondation pour la Recherche Médicale. 


\section{REFERENCES}

Acton, B. A., Mahadevan, V., Mercado, A., Uvarov, P., Ding, Y., Pressey, J., et al. (2012). Hyperpolarizing GABAergic transmission requires the KCC2 C-terminal ISO domain. J. Neurosci. 32, 8746-8751. doi: 10.1523/JNEUROSCI. 6089-11.2012

Agez, M., Schultz, P., Medina, I., Baker, D. J., Burnham, M. P., Cardarelli, R. A., et al. (2017). Molecular architecture of potassium chloride co-transporter KCC2. Sci. Rep. 7:16452. doi: 10.1038/s41598-017-15739-1

Aguado, F., Carmona, M. A., Pozas, E., Aguiló, A., Martínez-Guijarro, F. J., Alcantara, S., et al. (2003). BDNF regulates spontaneous correlated activity at early developmental stages by increasing synaptogenesis and expression of the $\mathrm{K}^{+} / \mathrm{Cl}^{-}$co-transporter KCC2. Development $130,1267-1280$. doi: $10.1242 / \mathrm{dev}$. 00351

Anggono, V., Koç-Schmitz, Y., Widagdo, J., Kormann, J., Quan, A., Chen, C.-M., et al. (2013). PICK1 interacts with PACSIN to regulate AMPA receptor internalization and cerebellar long-term depression. Proc. Natl. Acad. Sci. U S A 110, 13976-13981. doi: 10.1073/pnas. 1312467110

de Lores Arnaiz, G. R., and Ordieres, M. G. (2014). Brain $\mathrm{Na}^{+}, \mathrm{K}^{+}$-ATPase activity in aging and disease. Int. J. Biomed. Sci. 10, 85-102.

Báldi, R., Varga, C., and Tamás, G. (2010). Differential distribution of KCC2 along the axo-somato-dendritic axis of hippocampal principal cells. Eur. J. Neurosci. 32, 1319-1325. doi: 10.1111/j.1460-9568.2010.07361.x

Barthó, P., Payne, J. A., Freund, T. F., and Acsády, L. (2004). Differential distribution of the $\mathrm{KCl}$ cotransporter $\mathrm{KCC} 2$ in thalamic relay and reticular nuclei. Eur. J. Neurosci. 20, 965-975. doi: 10.1111/j.1460-9568.2004.03562.x

Berninger, B., Marty, S., Zafra, F., da Penha Berzaghi, M., Thoenen, H., and Lindholm, D. (1995). GABAergic stimulation switches from enhancing to repressing BDNF expression in rat hippocampal neurons during maturation in vitro. Development 121, 2327-2335.

Blaesse, P., Airaksinen, M. S., Rivera, C., and Kaila, K. (2009). Cation-chloride cotransporters and neuronal function. Neuron 61, 820-838. doi: 10.1016/j. neuron.2009.03.003

Blaesse, P., Guillemin, I., Schindler, J., Schweizer, M., Delpire, E., Khiroug, L., et al. (2006). Oligomerization of KCC2 correlates with development of inhibitory neurotransmission. J. Neurosci. 26, 10407-10419. doi: 10.1523/JNEUROSCI. 3257-06.2006

Bormann, J., Hamill, O. P., and Sakmann, B. (1987). Mechanism of anion permeation through channels gated by glycine and gamma-aminobutyric acid in mouse cultured spinal neurones. J. Physiol. 385, 243-286. doi: 10.1113/jphysiol.1987.sp016493

Buzsáki, G., Kaila, K., and Raichle, M. (2007). Inhibition and brain work. Neuron 56, 771-783. doi: 10.1016/j.neuron.2007.11.008

Carmona, M. A., Pozas, E., Martínez, A., Espinosa-Parrilla, J. F., Soriano, E., and Aguado, F. (2006). Age-dependent spontaneous hyperexcitability and impairment of GABAergic function in the hippocampus of mice lacking trkB. Cereb. Cortex 16, 47-63. doi: 10.1093/cercor/bhi083

Casula, S., Shmukler, B. E., Wilhelm, S., Stuart-Tilley, A. K., Su, W., Chernova, M. N., et al. (2001). A dominant negative mutant of the KCC1 K-Cl cotransporter: both $\mathrm{N}$ - and $\mathrm{C}$-terminal cytoplasmic domains are required for K-Cl cotransport activity. J. Biol. Chem. 276, 41870-41878. doi: 10.1074/jbc. M107155200

Casula, S., Zolotarev, A. S., Stuart-Tilley, A. K., Wilhelm, S., Shmukler, B. E., Brugnara, C., et al. (2009). Chemical crosslinking studies with the mouse Kcc1 K-Cl cotransporter. Blood Cells Mol. Dis. 42, 233-240. doi: 10.1016/j.bcmd. 2009.01.021

Chamma, I., Chevy, Q., Poncer, J. C., and Lévi, S. (2012). Role of the neuronal K-Cl co-transporter KCC2 in inhibitory and excitatory neurotransmission. Front. Cell. Neurosci. 6:5. doi: 10.3389/fncel.2012.00005

Chamma, I., Heubl, M., Chevy, Q., Renner, M., Moutkine, I., Eugène, E., et al. (2013). Activity-dependent regulation of the $\mathrm{K} / \mathrm{Cl}$ transporter KCC2 membrane diffusion, clustering and function in hippocampal neurons. J. Neurosci. 33, 15488-15503. doi: 10.1523/JNEUROSCI.5889-12.2013

Chavas, J., and Marty, A. (2003). Coexistence of excitatory and inhibitory GABA synapses in the cerebellar interneuron network. J. Neurosci. 23, 2019-2031. doi: 10.1523/jneurosci.23-06-02019.2003

Chevy, Q., Heubl, M., Goutierre, M., Backer, S., Moutkine, I., Eugène, E., et al. (2015). KCC2 gates activity-driven AMPA receptor traffic through cofilin phosphorylation. J. Neurosci. 35, 15772-15786. doi: 10.1523/JNEUROSCI. 1735-15.2015

Choquet, D., and Triller, A. (2013). The dynamic synapse. Neuron 80, 691-703. doi: 10.1016/j.neuron.2013.10.013

Conway, L. C., Cardarelli, R. A., Moore, Y. E., Jones, K., McWilliams, L. J., Baker, D. J., et al. (2017). N-Ethylmaleimide increases KCC2 cotrans- porter activity by modulating transporter phosphorylation. J. Biol. Chem. 292, 21253-21263. doi: 10.1074/jbc.m117.817841

Cordshagen, A., Busch, W., Winklhofer, M., Nothwang, H. G., and Hartmann, A. M. (2018). Phosphoregulation of the intracellular termini of $\mathrm{K}^{+}-\mathrm{Cl}^{-}$cotransporter 2 (KCC2) enables flexible control of its activity. J. Biol. Chem. 293, 16984-16993. doi: 10.1074/jbc.RA118.004349

de Los Heros, P., Alessi, D. R., Gourlay, R., Campbell, D. G., Deak, M., Macartney, T. J., et al. (2014). The WNK-regulated SPAK/OSR1 kinases directly phosphorylate and inhibit the $\mathrm{K}^{+}-\mathrm{Cl}^{-}$co-transporters. Biochem. J. 458, 559-573. doi: 10.1042/BJ20131478

Dubois, C. J., Cardoit, L., Schwarz, V., Markkanen, M., Airaksinen, M. S., Uvarov, P., et al. (2018). Role of the $\mathrm{K}^{+}-\mathrm{Cl}^{-}$cotransporter KCC2a isoform in Mammalian respiration at birth. eNeuro 5:ENEURO.0264-18.2018. doi: 10.1523/ENEURO.0264-18.2018

Dzhala, V. I., Talos, D. M., Sdrulla, D. A., Brumback, A. C., Mathews, G. C., Benke, T. A., et al. (2005). NKCC1 transporter facilitates seizures in the developing brain. Nat. Med. 11, 1205-1213. doi: 10.1038/nm1301

Ferando, I., Faas, G. C., and Mody, I. (2016). Diminished KCC2 confounds synapse specificity of LTP during senescence. Nat. Neurosci. 19, 1197-1200. doi: $10.1038 / \mathrm{nn} .4357$

Fiumelli, H., Briner, A., Puskarjov, M., Blaesse, P., Belem, B. J., Dayer, A. G., et al. (2013). An ion transport-independent role for the cation-chloride cotransporter kcc2 in dendritic spinogenesis in vivo. Cereb. Cortex 23, 378-388. doi: $10.1093 /$ cercor/bhs027

Fiumelli, H., Cancedda, L., and Poo, M. (2005). Modulation of GABAergic transmission by activity via postsynaptic $\mathrm{Ca}^{2+}$-dependent regulation of KCC2 function. Neuron 48, 773-786. doi: 10.1016/j.neuron.2005.10.025

Friedel, P., Kahle, K. T., Zhang, J., Hertz, N., Pisella, L. I., Buhler, E., et al. (2015). WNK1-regulated inhibitory phosphorylation of the KCC2 cotransporter maintains the depolarizing action of GABA in immature neurons. Sci. Signal. 8:ra65. doi: 10.1126/scisignal.aaa0354

Friedel, P., Ludwig, A., Pellegrino, C., Agez, M., Jawhari, A., Rivera, C., et al. (2017). A novel view on the role of intracellular tails in surface delivery of the potassium-chloride cotransporter KCC2. eNeuro 4:ENEURO.0055-17.2017. doi: 10.1523/ENEURO.0055-17.2017

Garbarini, N., and Delpire, E. (2008). The RCC1 domain of protein associated with myc (PAM) interacts with and regulates KCC2. Cell. Physiol. Biochem. 22, 31-44. doi: 10.1159/000149781

Gauvain, G., Chamma, I., Chevy, Q., Cabezas, C., Irinopoulou, T., Bodrug, N., et al. (2011). The neuronal K-Cl cotransporter KCC2 influences postsynaptic AMPA receptor content and lateral diffusion in dendritic spines. Proc. Natl. Acad. Sci. U S A 108, 15474-15479. doi: 10.1073/pnas.1107893108

Gottmann, K., Mittmann, T., and Lessmann, V. (2009). BDNF signaling in the formation, maturation and plasticity of glutamatergic and GABAergic synapses. Exp. Brain Res. 199, 203-234. doi: 10.1007/s00221-009-1994-z

Gu, J., Lee, C. W., Fan, Y., Komlos, D., Tang, X., Sun, C., et al. (2010). $\mathrm{ADF} / \mathrm{cofilin}$-mediated actin dynamics regulate AMPA receptor trafficking during synapticplasticity. Nat. Neurosci. 10, 1208-1215. doi: 10.1038/nn.2634

Gulyás, A. I., Sík, A., Payne, J. A., Kaila, K., and Freund, T. F. (2001). The KCl cotransporter, KCC2, is highly expressed in the vicinity of excitatory synapses in the rat hippocampus. Eur. J. Neurosci. 13, 2205-2217. doi: 10.1046/j.0953816x.2001.01600.x

Hamann, S., Herrera-Perez, J. J., Bundgaard, M., Alvarez-Leefmans, F. J., and Zeuthen, T. (2005). Water permeability of $\mathrm{Na}^{+}-\mathrm{K}^{+}-2 \mathrm{Cl}^{-}$cotransporters in mammalian epithelial cells. J. Physiol. 568, 123-135. doi: 10.1113/jphysiol.2005. 093526

Harris, J. J., Jolivet, R., and Attwell, D. (2012). Synaptic energy use and supply. Neuron 75, 762-777. doi: 10.1016/j.neuron.2012.08.019

Hartmann, A.-M., Blaesse, P., Kranz, T., Wenz, M., Schindler, J., Kaila, K., et al. (2009). Opposite effect of membrane raft perturbation on transport activity of KCC2 and NKCC1. J. Neurochem. 111, 321-331. doi: 10.1111/j.1471-4159. 2009.06343.x 
Hartmann, A.-M., and Nothwang, H. G. (2015). Molecular and evolutionary insights into the structural organization of cation chloride cotransporters. Front. Cell. Neurosci. 8:470. doi: 10.3389/fncel.2014.00470

Hartmann, A.-M., Wenz, M., Mercado, A., Störger, C., Mount, D. B., Friauf, E., et al. (2010). Differences in the large extracellular loop between the $\mathrm{K}^{+}$$\mathrm{Cl}^{-}$cotransporters KCC2 and KCC4. J. Biol. Chem. 285, 23994-24002. doi: $10.1074 /$ jbc.m110.144063

Heubl, M., Zhang, J., Pressey, J. C., Al Awabdh, S., Renner, M., Gomez-Castro, F., et al. (2017). GABAAreceptor dependent synaptic inhibition rapidly tunes KCC2 activity via the $\mathrm{Cl}^{-}$-sensitive WNK1 kinase. Nat. Commun. 8:1776. doi: 10.1038/s41467-017-01749-0

Horn, Z., Ringstedt, T., Blaesse, P., Kaila, K., and Herlenius, E. (2010). Premature expression of KCC2 in embryonic mice perturbs neural development by an ion transport-independent mechanism. Eur. J. Neurosci. 31, 2142-2155. doi: 10.1111/j.1460-9568.2010.07258.x

Howarth, C., Gleeson, P., and Attwell, D. (2012). Updated energy budgets for neural computation in the neocortex and cerebellum. J. Cereb. Blood Flow Metab. 32, 1222-1232. doi: $10.1038 / \mathrm{jcbfm} .2012 .35$

Howard, H. C., Mount, D. B., Rochefort, D., Byun, N., Dupré, N., Lu, J., et al. (2002). The $\mathrm{K}-\mathrm{Cl}$ cotransporter KCC3 is mutant in a severe peripheral neuropathy associated with agenesis of the corpus callosum. Nat. Genet. 32, 384-392. doi: $10.1038 / \mathrm{ng} 1002$

Hübner, C. A., Stein, V., Hermans-Borgmeyer, I., Meyer, T., Ballanyi, K., and Jentsch, T. J. (2001). Disruption of KCC2 reveals an essential role of $\mathrm{K}-\mathrm{Cl}$ cotransport already in early synaptic inhibition. Neuron $30,515-524$. doi: 10.1016/s0896-6273(01)00297-5

Ivakine, E. A., Acton, B. A., Mahadevan, V., Ormond, J., Tang, M., Pressey, J. C., et al. (2013). Neto2 is a KCC2 interacting protein required for neuronal $\mathrm{Cl}^{-}$regulation in hippocampal neurons. Proc. Natl. Acad. Sci. U S A 110, 3561-3566. doi: 10.1073/pnas.1212907110

Kahle, K. T., and Delpire, E. (2016). Kinase-KCC2 coupling: $\mathrm{Cl}^{-}$rheostasis, disease susceptibility, therapeutic target. J. Neurophysiol. 115, 8-18. doi: $10.1152 /$ jn.00865.2015

Kaila, K., Price, T. J., Payne, J. A., Puskarjov, M., and Voipio, J. (2014). Cationchloride cotransporters in neuronal development, plasticity and disease. Nat. Rev. Neurosci. 15, 637-654. doi: 10.1038/nrn3819

Kaila, K., and Voipio, J. (1987). Postsynaptic fall in intracellular pH induced by GABA-activated bicarbonate conductance. Nature 330, 163-165. doi: $10.1038 / 330163 \mathrm{a} 0$

Karadsheh, M. F., and Delpire, E. (2001). Neuronal restrictive silencing element is found in the KCC2 gene: molecular basis for KCC2-specific expression in neurons. J. Neurophysiol. 85, 995-997. doi: 10.1152/jn.2001.85. 2.995

Kelsch, W., Hormuzdi, S., Straube, E., Lewen, A., Monyer, H., and Misgeld, U. (2001). Insulin-like growth factor 1 and a cytosolic tyrosine kinase activate chloride outward transport during maturation of hippocampal neurons. J. Neurosci. 21, 8339-8347. doi: 10.1523/jneurosci.21-21-083 39.2001

Kitamura, A., Ishibashi, H., Watanabe, M., Takatsuru, Y., Brodwick, M., and Nabekura, J. (2008). Sustained depolarizing shift of the GABA reversal potential by glutamate receptor activation in hippocampal neurons. Neurosci. Res. 62, 270-277. doi: 10.1016/j.neures.2008.09.002

Kuczewski, N., Fuchs, C., Ferrand, N., Jovanovic, J. N., Gaiarsa, J. L., and Porcher, C. (2011). Mechanism of GABAB receptor-induced BDNF secretion and promotion of $\mathrm{GABA}_{\mathrm{A}}$ receptor membrane expression. J. Neurochem. 118, 533-545. doi: 10.1111/j.1471-4159.2011.07192.x

Lee, H. H. C., Deeb, T. Z., Walker, J. A., Davies, P. A., and Moss, S. J. (2011). NMDA receptor activity downregulates KCC2 resulting in depolarizing $\mathrm{GABA}_{\mathrm{A}}$ receptor-mediated currents. Nat. Neurosci. 14, 736-743. doi: $10.1038 / \mathrm{nn} .2806$

Lee, H. H. C., Jurd, R., and Moss, S. J. (2010). Tyrosine phosphorylation regulates the membrane trafficking of the potassium chloride co-transporter KCC2. Mol. Cell. Neurosci. 45, 173-179. doi: 10.1016/j.mcn.2010.06.008

Lee, H. H. C., Walker, J. A., Williams, J. R., Goodier, R. J., Payne, J. A., and Moss, S. J. (2007). Direct protein kinase C-dependent phosphorylation regulates the cell surface stability and activity of the potassium chloride cotransporter KCC2. J. Biol. Chem. 282, 29777-29784. doi: 10.1074/jbc. M705053200
Li, H., Khirug, S., Cai, C., Ludwig, A., Blaesse, P., Kolikova, J., et al. (2007). KCC2 interacts with the dendritic cytoskeleton to promote spine development. Neuron 56, 1019-1033. doi: 10.1016/j.neuron.2007.10.039

Li, H., Tornberg, J., Kaila, K., Airaksinen, M. S., and Rivera, C. (2002). Patterns of cation-chloride cotransporter expression during embryonic rodent CNS development. Eur. J. Neurosci. 16, 2358-2370. doi: 10.1046/j.1460-9568.2002. 02419.x

Li, X., Zhou, J., Chen, Z., Chen, S., Zhu, F., and Zhou, L. (2008). Long-term expressional changes of $\mathrm{Na}^{+}-\mathrm{K}^{+}-\mathrm{Cl}^{-}$co-transporter 1 (NKCC1) and $\mathrm{K}^{+}-\mathrm{Cl}^{-}$ co-transporter 2 (KCC2) in CA1 region of hippocampus following lithiumpilocarpine induced status epilepticus (PISE). Brain Res. 1221, 141-146. doi: 10.1016/j.brainres.2008.04.047

Llano, O., Smirnov, S., Soni, S., Golubtsov, A., Guillemin, I., Hotulainen, P., et al. (2015). KCC2 regulates actin dynamics in dendritic spines via interaction with ß-PIX. J. Cell Biol. 209, 671-686. doi: 10.1083/jcb.201411008

Ludwig, A., Li, H., Saarma, M., Kaila, K., and Rivera, C. (2003). Developmental up-regulation of KCC2 in the absence of GABAergic and glutamatergic transmission. Eur. J. Neurosci. 18, 3199-3206. doi: 10.1111/j.1460-9568.2003. 03069.x

Ludwig, A., Uvarov, P., Pellegrino, C., Thomas-Crusells, J., Schuchmann, S., Saarma, M., et al. (2011). Neurturin evokes MAPK-dependent upregulation of Egr4 and KCC2 in developing neurons. Neural Plast. 2011, 1-8. doi: 10.1155/2011/641248

Mahadevan, V., Khademullah, C. S., Dargaei, Z., Chevrier, J., Uvarov, P., Kwan, J., et al. (2017). Native KCC2 interactome reveals PACSIN1 as a critical regulator of synaptic inhibition. Elife 6:e28270. doi: 10.7554/eLife.28270

Mahadevan, V., Pressey, J. C., Acton, B. A., Uvarov, P., Huang, M. Y., Chevrier, J., et al. (2014). Kainate receptors coexist in a functional complex with KCC2 and regulate chloride homeostasis in hippocampal neurons. Cell Rep. 7, 1762-1770. doi: 10.1016/j.celrep.2014.05.022

Markkanen, M., Karhunen, T., Llano, O., Ludwig, A., Rivera, C., Uvarov, P., et al. (2014). Distribution of neuronal KCC2a and KCC2b isoforms in mouse CNS. J. Comp. Neurol. 522, 1897-1914. doi: 10.1002/cne.23510

Markkanen, M., Ludwig, A., Khirug, S., Pryazhnikov, E., Soni, S., Khiroug, L., et al. (2017). Implications of the N-terminal heterogeneity for the neuronal $\mathrm{K}-\mathrm{Cl}$ cotransporter KCC2 function. Brain Res. 1675, 87-101. doi: 10.1016/j.brainres. 2017.08.034

Markkanen, M., Uvarov, P., and Airaksinen, M. S. (2008). Role of upstream stimulating factors in the transcriptional regulation of the neuron-specific $\mathrm{K}-\mathrm{Cl}$ cotransporter KCC2. Brain Res. 1236, 8-15. doi: 10.1016/j.brainres.2008.08.007

McCormick, J. A., and Ellison, D. H. (2011). The WNKs: atypical protein kinases with pleiotropic actions. Physiol. Rev. 91, 177-219. doi: 10.1152/physrev.00017. 2010

Medina, I., Friedel, P., Rivera, C., Kahle, K. T., Kourdougli, N., Uvarov, P., et al. (2014). Current view on the functional regulation of the neuronal $\mathrm{K}^{+}-\mathrm{Cl}^{-}$ cotransporter KCC2. Front. Cell. Neurosci. 8:27. doi: 10.3389/fncel.2014.00027

Mercado, A., Broumand, V., Zandi-Nejad, K., Enck, A. H., and Mount, D. B. (2006). A C-terminal domain in KCC2 confers constitutive $\mathrm{K}^{+}-\mathrm{Cl}^{-}$ cotransport. J. Biol. Chem. 281, 1016-1026. doi: 10.1074/jbc.M509972200

Moore, Y. E., Deeb, T. Z., Chadchankar, H., Brandon, N. J., and Moss, S. J. (2018). Potentiating KCC2 activity is sufficient to limit the onset and severity of seizures. Proc. Natl. Acad. Sci. U S A 115, 10166-10171. doi: 10.1073/pnas. 1810134115

Moore, Y. E., Kelley, M. R., Brandon, N. J., Deeb, T. Z., and Moss, S. J. (2017). Seizing control of KCC2: a new therapeutic target for epilepsy. Trends Neurosci. 40, 555-571. doi: 10.1016/j.tins.2017.06.008

Moore-Hoon, M. L., and Turner, R. J. (2000). The structural unit of the secretory $\mathrm{Na}^{+}-\mathrm{K}^{+}-2 \mathrm{Cl}^{-}$cotransporter (NKCC1) is a homodimer. Biochemistry 39, 3718-3724. doi: 10.1021/bi992301v

Pathak, H. R., Weissinger, F., Terunuma, M., Carlson, G. C., Hsu, F.-C., Moss, S. J., et al. (2007). Disrupted dentate granule cell chloride regulation enhances synaptic excitability during development of temporal lobe epilepsy. J. Neurosci. 27, 14012-14022. doi: 10.1523/JNEUROSCI.4390-07.2007

Payne, J. A. (1997). Functional characterization of the neuronal-specific K-Cl cotransporter: implications for $\left[\mathrm{K}^{+}\right]_{\mathrm{o}}$ regulation. Am. J. Physiol. 273, C1516-C1525. doi: 10.1152/ajpcell.1997.273.5.c1516

Petrini, E. M., Ravasenga, T., Hausrat, T. J., Iurilli, G., Olcese, U., Racine, V., et al. (2014). Synaptic recruitment of gephyrin regulates surface GABAA 
receptor dynamics for the expression of inhibitory LTP. Nat. Commun. 5:3921. doi: $10.1038 /$ ncomms 4921

Piala, A. T., Moon, T. M., Akella, R., He, H., Cobb, M. H., and Goldsmith, E. J. (2014). Chloride sensing by WNK1 involves inhibition of autophosphorylation. Sci. Signal. 7:ra41. doi: 10.1126/scisignal.2005050

Piechotta, K., Lu, J., and Delpire, E. (2002). Cation chloride cotransporters interact with the stress-related kinases Ste20-related proline-alanine-rich kinase (SPAK) and oxidative stress response 1 (OSR1). J. Biol. Chem. 277, 50812-50819. doi: 10.1074/jbc.M208108200

Poncer, J. C. (2003). Hippocampal long term potentiation: silent synapses and beyond. J. Physiol. Paris 97, 415-422. doi: 10.1016/j.jphysparis.2004.01.003

Poo, M. M. (2001). Neurotrophins as synaptic modulators. Nat. Rev. Neurosci. 2, 24-32. doi: 10.1038/35049004

Porcher, C., Hatchett, C., Longbottom, R. E., McAinch, K., Sihra, T. S., Moss, S. J., et al. (2011). Positive feedback regulation between gamma-aminobutyric acid type $\mathrm{A}\left(\mathrm{GABA}_{A}\right)$ receptor signaling and brain-derived neurotrophic factor (BDNF) release in developing neurons. J. Biol. Chem. 286, 21667-21677. doi: 10.1074/jbc.M110.201582

Pressey, J. C., Mahadevan, V., Khademullah, C. S., Dargaei, Z., Chevrier, J., Ye, W., et al. (2017). A kainate receptor subunit promotes the recycling of the neuronspecific $\mathrm{K}^{+}-\mathrm{Cl}^{-}$co-transporter KCC2 in hippocampal neurons. J. Biol. Chem. 292, 6190-6201. doi: 10.1074/jbc.M116.767236

Price, G. D., and Trussell, L. O. (2006). Estimate of the chloride concentration in a central glutamatergic terminal: a gramicidin perforated-patch study on the calyx of held. J. Neurosci. 26, 11432-11436. doi: 10.1523/JNEUROSCI.166006.2006

Pugh, J. R., and Jahr, C. E. (2011). Axonal GABA $A_{A}$ receptors increase cerebellar granule cell excitability and synaptic activity. J. Neurosci. 31, 565-574. doi: 10.1523/JNEUROSCI.4506-10.2011

Pugh, J. R., and Jahr, C. E. (2013). Activation of axonal receptors by GABA spillover increases somatic firing. J. Neurosci. 33, 16924-16929. doi: 10.1523/JNEUROSCI.2796-13.2013

Puskarjov, M., Ahmad, F., Kaila, K., and Blaesse, P. (2012). Activity-dependent cleavage of the $\mathrm{K}-\mathrm{Cl}$ cotransporter KCC2 mediated by calcium-activated protease calpain. J. Neurosci. 32, 11356-11364. doi: 10.1523/JNEUROSCI.626511.2012

Puskarjov, M., Ahmad, F., Khirug, S., Sivakumaran, S., Kaila, K., and Blaesse, P. (2015). BDNF is required for seizure-induced but not developmental up-regulation of KCC2 in the neonatal hippocampus. Neuropharmacology 88, 103-109. doi: 10.1016/j.neuropharm.2014.09.005

Reid, K. H., Li, G. Y., Payne, R. S., Schurr, A., and Cooper, N. G. F. (2001). The mRNA level of the potassium-chloride cotransporter KCC2 covaries with seizure susceptibility in inferior colliculus of the post-ischemic audiogenic seizure-prone rat. Neurosci. Lett. 308, 29-32. doi: 10.1016/s03043940(01)01973-5

Rinehart, J., Maksimova, Y. D., Tanis, J. E., Stone, K. L., Hodson, C. A., Zhang, J., et al. (2009). Sites of regulated phosphorylation that control K-Cl cotransporter activity. Cell 138, 525-536. doi: 10.1016/j.cell.2009.05.031

Rivera, C., Li, H., Thomas-Crusells, J., Lahtinen, H., Viitanen, T., Nanobashvili, A., et al. (2002). BDNF-induced TrkB activation down-regulates the $\mathrm{K}^{+}-\mathrm{Cl}^{-}$ cotransporter KCC2 and impairs neuronal $\mathrm{Cl}^{-}$extrusion. J. Cell Biol. 159, 747-752. doi: 10.1083/jcb.200209011

Rivera, C., Voipio, J., Payne, J. A., Ruusuvuori, E., Lahtinen, H., Lamsa, K., et al. (1999). The $\mathrm{K}^{+} / \mathrm{Cl}^{-}$co-transporter $\mathrm{KCC} 2$ renders GABA hyperpolarizing during neuronal maturation. Nature 397, 251-255. doi: 10.1038/16697

Rivera, C., Voipio, J., Thomas-Crusells, J., Li, H., Emri, Z., Sipilä, S., et al. (2004). Mechanism of activity-dependent downregulation of the neuron-specific K-Cl cotransporter KCC2. J. Neurosci. 24, 4683-4691. doi: 10.1523/jneurosci.526503.2004

Roussa, E., Speer, J. M., Chudotvorova, I., Khakipoor, S., Smirnov, S., Rivera, C., et al. (2016). The membrane trafficking and functionality of the $\mathrm{K}^{+}{ }_{-} \mathrm{Cl}^{-}$ co-transporter KCC2 is regulated by TGF- $\beta 2$. J. Cell Sci. 129, 3485-3498. doi: $10.1242 /$ jcs. 189860

Ruiz, A., Campanac, E., Scott, R. S., Rusakov, D. A., and Kullmann, D. M. (2010). Presynaptic $\mathrm{GABA}_{\mathrm{A}}$ receptors enhance transmission and LTP induction at hippocampal mossy fiber synapses. Nat. Neurosci. 13, 431-438. doi: $10.1038 / \mathrm{nn} .2512$

Schael, S., Nüchel, J., Müller, S., Petermann, P., Kormann, J., Pérez-Otaño, I., et al. (2013). Casein kinase 2 phosphorylation of protein kinase $\mathrm{C}$ and casein kinase
2 substrate in neurons (PACSIN) 1 protein regulates neuronal spine formation. J. Biol. Chem. 288, 9303-9312. doi: 10.1074/jbc.m113.461293

Sedmak, G., Jovanov-Miloševic, N., Puskarjov, M., Ulamec, M., Krušlin, B., Kaila, K., et al. (2016). Developmental expression patterns of KCC2 and functionally associated molecules in the human brain. Cereb. Cortex 26, 4574-4589. doi: 10.1093/cercor/bhv218

Shimizu-Okabe, C., Tanaka, M., Matsuda, K., Mihara, T., Okabe, A., Sato, K., et al. (2011). KCC2 was downregulated in small neurons localized in epileptogenic human focal cortical dysplasia. Epilepsy Res. 93, 177-184. doi: 10.1016/j. eplepsyres.2010.12.008

Silayeva, L., Deeb, T. Z., Hines, R. M., Kelley, M. R., Munoz, M. B., Lee, H. H. C., et al. (2015). KCC2 activity is critical in limiting the onset and severity of status epilepticus. Proc. Natl. Acad. Sci. U S A 112, 3523-3528. doi: 10.1073/pnas. 1415126112

Simard, C. F., Bergeron, M. J., Frenette-Cotton, R., Carpentier, G. A., Pelchat, M.E., Caron, L., et al. (2007). Homooligomeric and heterooligomeric associations between $\mathrm{K}^{+}-\mathrm{Cl}^{-}$cotransporter isoforms and between $\mathrm{K}^{+}-\mathrm{Cl}^{-}$and $\mathrm{Na}^{+}$ $\mathrm{K}^{+}-\mathrm{Cl}^{-}$cotransporters. J. Biol. Chem. 282, 18083-18093. doi: 10.1074/jbc. $\mathrm{m} 607811200$

Simard, C. F., Brunet, G. M., Daigle, N. D., Montminy, V., Caron, L., and Isenring, P. (2004). Self-interacting domains in the C terminus of a cation$\mathrm{Cl}^{-}$cotransporter described for the first time. J. Biol. Chem. 279, 40769-40777. doi: $10.1074 /$ jbc.m406458200

Starremans, P. G. J. F., Kersten, F. F. J., Van Den Heuvel, L. P. W. J., Knoers, N. V. A. M., and Bindels, R. J. M. (2003). Dimeric architecture of the human bumetanide-sensitive Na-K-Cl co-transporter. J. Am. Soc. Nephrol. 14, 3039-3046. doi: 10.1097/01.asn.0000097370.29737.5b

Stein, V., Hermans-Borgmeyer, I., Jentsch, T. J., and Hübner, C. A. (2004). Expression of the $\mathrm{KCl}$ cotransporter $\mathrm{KCC} 2$ parallels neuronal maturation and the emergence of low intracellular chloride. J. Comp. Neurol. 468, 57-64. doi: 10.1002/cne.10983

Stell, B. M. (2011). Biphasic action of axonal GABA-A receptors on presynaptic calcium influx. J. Neurophysiol. 105, 2931-2936. doi: 10.1152/jn.01125.2010

Stell, B. M., Rostaing, P., Triller, A., and Marty, A. (2007). Activation of presynaptic $\mathrm{GABA}_{\mathrm{A}}$ Receptors Induces glutamate release from parallel fiber synapses. J. Neurosci. 27, 9022-9031. doi: 10.1523/jneurosci.1954-07.2007

Stödberg, T., McTague, A., Ruiz, A. J., Hirata, H., Zhen, J., Long, P., et al. (2015). Mutations in SLC12A5 in epilepsy of infancy with migrating focal seizures. Nat. Commun. 6:8038. doi: 10.1038/ncomms9038

Szabadics, J., Varga, C., Molnár, G., Oláh, S., Barzó, P., and Tamás, G. (2006). Excitatory effect of GABAergic axo-axonic cells in cortical microcircuits. Science 311, 233-235. doi: 10.1126/science.1121325

Tanis, J. E., Bellemer, A., Moresco, J. J., Forbush, B., and Koelle, M. R. (2009). The potassium chloride cotransporter KCC-2 coordinates development of inhibitory neurotransmission and synapse structure in Caenorhabditis elegans. J. Neurosci. 29, 9943-9954. doi: 10.1523/jneurosci.1989-09.2009

Terker, A. S., Zhang, C., Erspamer, K. J., Gamba, G., Yang, C.-L., and Ellison, D. H. (2016). Unique chloride-sensing properties of WNK4 permit the distal nephron to modulate potassium homeostasis. Kidney Int. 89, 127-134. doi: 10.1038/ki. 2015.289

Uvarov, P., Ludwig, A., Markkanen, M., Pruunsild, P., Kaila, K., Delpire, E., et al. (2007). A novel N-terminal isoform of the neuron-specific $\mathrm{K}-\mathrm{Cl}$ cotransporter KCC2. J. Biol. Chem. 282, 30570-30576. doi: 10.1074/jbc.M705095200

Uvarov, P., Ludwig, A., Markkanen, M., Rivera, C., and Airaksinen, M. S. (2006). Upregulation of the neuron-specific $\mathrm{K}^{+} / \mathrm{Cl}^{-}$cotransporter expression by transcription factor early growth response 4. J. Neurosci. 26, 13463-13473. doi: 10.1523/jneurosci.4731-06.2006

Uvarov, P., Ludwig, A., Markkanen, M., Soni, S., Hübner, C. A., Rivera, C., et al. (2009). Coexpression and heteromerization of two neuronal $\mathrm{K}-\mathrm{Cl}$ cotransporter isoforms in neonatal brain. J. Biol. Chem. 284, 13696-13704. doi: $10.1074 /$ jbc.m807366200

Uvarov, P., Pruunsild, P., Timmusk, T., and Airaksinen, M. S. (2005). Neuronal $\mathrm{K}^{+} / \mathrm{Cl}^{-}$co-transporter (KCC2) transgenes lacking neurone restrictive silencer element recapitulate CNS neurone-specific expression and developmental up-regulation of endogenous KCC2 gene. J. Neurochem. 95, 1144-1155. doi: 10.1111/j.1471-4159.2005.03434.x

Vardi, N., Zhang, L. L., Payne, J. A., and Sterling, P. (2000). Evidence that different cation chloride cotransporters in retinal neurons allow opposite responses to GABA. J. Neurosci. 20, 7657-7663. doi: 10.1523/jneurosci.20-20-07657.2000 
Vitari, A. C., Thastrup, J., Rafiqi, F. H., Deak, M., Morrice, N. A., Karlsson, H. K. R., et al. (2006). Functional interactions of the SPAK/OSR1 kinases with their upstream activator WNK1 and downstream substrate NKCC1. Biochem. J. 397, 223-231. doi: 10.1042/bj20060220

Wang, W., Gong, N., and Xu, T. L. (2006a). Downregulation of KCC2 following LTP contributes to EPSP-spike potentiation in rat hippocampus. Biochem. Biophys. Res. Commun. 343, 1209-1215. doi: 10.1016/j.bbrc.2006.03.038

Wang, L., Kitai, S. T., and Xiang, Z. (2006b). Activity-dependent bidirectional modification of inhibitory synaptic transmission in rat subthalamic neurons. J. Neurosci. 26, 7321-7327. doi: 10.1523/jneurosci.4656-05.2006

Wang, Y., Wang, Y., and Chen, Z. (2018). Double-edged GABAergic synaptic transmission in seizures: the importance of chloride plasticity. Brain Res. 1701, 126-136. doi: 10.1016/j.brainres.2018.09.008

Warmuth, S., Zimmermann, I., and Dutzler, R. (2009). X-ray structure of the C-terminal domain of a prokaryotic cation-chloride cotransporter. Structure 17, 538-546. doi: 10.1016/j.str.2009.02.009

Watanabe, M., and Fukuda, A. (2015). Development and regulation of chloride homeostasis in the central nervous system. Front. Cell. Neurosci. 9:371. doi: 10.3389/fncel.2015.00371

Watanabe, M., Wake, H., Moorhouse, A. J., and Nabekura, J. (2009). Clustering of neuronal $\mathrm{K}^{+}-\mathrm{Cl}^{-}$cotransporters in lipid rafts by tyrosine phosphorylation. J. Biol. Chem. 284, 27980-27988. doi: 10.1074/jbc.m109.043620

Weber, M., Hartmann, A.-M., Beyer, T., Ripperger, A., and Nothwang, H. G. (2014). A novel regulatory locus of phosphorylation in the C-terminus of the potassium chloride cotransporter KCC2 that interferes with $\mathrm{N}$-ethylmaleimide or staurosporine mediated activation. J. Biol. Chem. 289, 18668-18679. doi: 10.1074/jbc.M114.567834

Widagdo, J., Fang, H., Jang, S. E., and Anggono, V. (2016). PACSIN1 regulates the dynamics of AMPA receptor trafficking. Sci. Rep. 6:31070. doi: 10.1038/srep 31070

Williams, J. R., Sharp, J. W., Kumari, V. G., Wilson, M., and Payne, J. A. (1999). The neuron-specific K-Cl cotransporter, KCC2: antibody development and initial characterization of the protein. J. Biol. Chem. 274, 12656-12664. doi: $10.1074 /$ jbc. 274.18 .12656

Woo, N.-S., Lu, J., England, R., McClellan, R., Dufour, S., Mount, D. B., et al. (2002). Hyperexcitability and epilepsy associated with disruption of the mouse neuronal-specific K-Cl cotransporter gene. Hippocampus 12, 258-268. doi: 10.1002/hipo.10014

Woodin, M. A., Ganguly, K., and Poo, M. M. (2003). Coincident preand postsynaptic activity modifies GABAergic synapses by postsynaptic changes in $\mathrm{Cl}^{-}$transporter activity. Neuron 39, 807-820. doi: 10.1016/s08966273(03)00507-5

Yeo, M., Berglund, K., Augustine, G., and Liedtke, W. (2009). Novel repression of Kcc2 transcription by REST-RE-1 controls developmental switch in neuronal chloride. J. Neurosci. 29, 14652-14662. doi: 10.1523/JNEUROSCI.293409.2009
Zagórska, A., Pozo-Guisado, E., Boudeau, J., Vitari, A. C., Rafiqi, F. H., Thastrup, J., et al. (2007). Regulation of activity and localization of the WNK1 protein kinase by hyperosmotic stress. J. Cell Biol. 176, 89-100. doi: $10.1083 /$ jcb.200605093

Zeuthen, T. (1991a). Water permeability of ventricular cell membrane in choroid plexus epithelium from necturus maculosus. J. Physiol. 444, 133-151. doi: 10.1113/jphysiol.1991.sp018870

Zeuthen, T. (1991b). Secondary active transport of water across ventricular cell membrane of choroid plexus epithelium of Necturus maculosus. J. Physiol. 444, 153-173. doi: 10.1113/jphysiol.1991.sp018871

Zeuthen, T., and Macaulay, N. (2012). Cotransport of water by $\mathrm{Na}^{+}-\mathrm{K}^{+}$. $2 \mathrm{Cl}^{-}$cotransporters expressed in Xenopus oocytes: NKCC1 versus NKCC2. J. Physiol. 590, 1139-1154. doi: 10.1113/jphysiol.2011.226316

Zhang, Y., Cudmore, R. H., Lin, D.-T., Linden, D. J., and Huganir, R. L. (2015). Visualization of NMDA receptor-dependent AMPA receptor synaptic plasticity in vivo. Nat. Neurosci. 18, 402-407. doi: 10.1038/nn.3936

Zhang, L. L., Fina, M. E., and Vardi, N. (2006). Regulation of KCC2 and NKCC during development: membrane insertion and differences between cell types. J. Comp. Neurol. 499, 132-143. doi: 10.1002/cne.21100

Zhang, J., Gao, G., Begum, G., Wang, J., Khanna, A. R., Shmukler, B. E., et al. (2016). Functional kinomics establishes a critical node of volume-sensitive cation- $\mathrm{Cl}^{-}$cotransporter regulation in the mammalian brain. Sci. Rep. 6:35986. doi: $10.1038 /$ srep35986

Zhang, R., Wei, H., Xia, Y., and Du, J. (2010). Development of light response and GABAergic excitation-to-inhibition switch in zebrafish retinal ganglion cells. J. Physiol. 588, 2557-2569. doi: 10.1113/jphysiol.2010.187088

Zhao, B., Wong, A. Y. C., Murshid, A., Bowie, D., Presley, J. F., and Bedford, F. K. (2008). Identification of a novel di-leucine motif mediating $\mathrm{K}^{+} / \mathrm{Cl}^{-}$cotransporter KCC2 constitutive endocytosis. Cell. Signal. 20, 1769-1779. doi: 10.1016/j.cellsig.2008.06.011

Zhou, H.-Y., Chen, S.-R., Byun, H.-S., Chen, H., Li, L., Han, H.-D., et al. (2012). $\mathrm{N}$-methyl-D-aspartate receptor- and calpain-mediated proteolytic cleavage of $\mathrm{K}^{+}-\mathrm{Cl}^{-}$cotransporter-2 impairs spinal chloride homeostasis in neuropathic pain. J. Biol. Chem. 287, 33853-33864. doi: 10.1074/jbc.m112.395830

Conflict of Interest Statement: The authors declare that the research was conducted in the absence of any commercial or financial relationships that could be construed as a potential conflict of interest.

Copyright (C) 2019 Côme, Heubl, Schwartz, Poncer and Lévi. This is an open-access article distributed under the terms of the Creative Commons Attribution License (CC BY). The use, distribution or reproduction in other forums is permitted, provided the original author(s) and the copyright owner(s) are credited and that the original publication in this journal is cited, in accordance with accepted academic practice. No use, distribution or reproduction is permitted which does not comply with these terms. 